\title{
Upward interfacial friction factor in gas and high-viscosity liquid flows in vertical pipes
}

Joseph Xavier Francisco Ribeiro a, b, Ruiquan Liao ${ }^{\text {a, b }}$, Aliyu M. Aliyu ${ }^{\text {c }}$, Zilong Liu ${ }^{\text {a, b }}$

a. Petroleum Engineering College, Yangtze University, 430100 Wuhan Hubei, China

b. Laboratory of Multiphase Flow, Gas Lift Innovation Centre, China National Petroleum Corporation

c. Faculty of Engineering, University of Nottingham, NG7 2RD, United Kingdom.

Joseph X. F. Ribeiro (Corresponding author), joxaro@yahoo.com, +233244476160; Ruiquan Liao, 1036792057@qq.com; Aliyu M. Aliyu, ali.aliyu@nottingham.ac.uk; Liu Zilong, zilongliu@yahoo.com

\begin{abstract}
In this study, experiments were carried out in a vertical 60-mm internal diameter pipe with air and oil (viscosities 100-330 mPa s) constituting the gas and liquid phases. Superficial air and oil velocity ranges used were $9.81-59.06 \mathrm{~m} / \mathrm{s}$ and $0.024-0.165 \mathrm{~m} / \mathrm{s}$ respectively. Visual observations and change in slope of pressure drop- $V_{s g}$ plot were used to identify flow pattern transition to annular flow. Using the experimental data as well as other reported data, a new correlation to predict interfacial friction factor in upward gas-viscous liquid annular flow regime was developed. Compared to the performance of 16 existing correlations using higher viscosity liquids, that of the new correlation was better. The performance of another correlation we derived for predictions at both low and higher low viscous showed good agreement with measurements. In addition, a neural network model to predict the interfacial friction factor involving both low and high viscous liquids was developed and it excellently described the experimental data.
\end{abstract}

Keywords: artificial intelligence, interfacial phenomena, liquid holdup, multiphase flow, pipe flow, two-phase flow 


\subsection{Introduction}

\subsection{Synopsis}

Gas-liquid two-phase upward annular flow in vertical pipes is a common phenomenon. A plethora of industrial occurrences include refrigerant flow in air-conditioning and refrigeration systems, transportation of oil and gas products in petroleum industries and steam in power plants as well as nuclear reactor core cooling. Generally, annular flow is characterized by a thin liquid film flowing along a pipe periphery and gas flow in the core region. Due to the practical importance of this regime coupled with the comparative ease with which analytical deductions can be applied, the annular flow pattern has been extensively investigated both experimentally and analytically (Wongwises and Kongkiatwanitch, 2001). Studies indicate that during annular flow, liquid droplet entrainment occurs in the gas core due to breakup of disturbance waves. This phenomenon strongly influences mass, momentum and energy transfer (Fore et al., 2000; Wongwises and Kongkiatwanitch, 2001).

One key parameter characterising the interface in annular flow and also governs transport phenomena between the liquid and gas phases is the interfacial shear stress. It is directly related to the flow variables: superficial velocities, core droplet fraction, the liquid film thickness, as well the interfacial friction factor. This relationship plays a key role in modelling the flow. Empirical modelling of the interfacial shear stress has been done quite extensively in the past few decades, especially in cases where the assumption is that the liquid travels entirely as a film and little or no liquid is entrained in the gas core. Some early works in this area include those of Wallis (1969), Asali et al. (1985), Fukano and Furukawa (1998) and Fore et al. (2000).

In addition to analytical models, models based on the physical behaviour of the fluids (for instance, two- or three-fluid models) are often solved using numerical methods to estimate pressure drop 
and phase fractions. These models necessarily require closure laws or correlations for the interfacial friction factor which is present in the force balance that connects the turbulent gas core and the wavy film. This makes the interfacial friction factor closure equation an important one that deserves particular attention (Aliyu et al., 2017). We note from the outset that the two-phase friction factor differs from the interfacial friction factor. In the case of the former, mixture flowing in the pipe is assumed to be homogeneous and may be regime independent, hence, appropriate defining properties of the mixture including viscosity, density and velocity are utilized. In contrast, in the case of interfacial friction factor, the gas core properties are used, where the momentum balance integrates the behaviour of the liquid film and not the pipe wall. ( Aliyu, 2015; Fore et al., 2000; Wongwises and Kongkiatwanitch, 2001).

One of the pioneering studies focussed on investigating interfacial friction factor in annular flow is that of Wallis (1969), who employed the single-phase flow analogy to develop a correlation (a linear approximation) for turbulent flow in rough pipes. Other researchers (Henstock and Hanratty, 1976; Asali et al., 1985; Fore et al., 2000; Belt et al., 2009) later demonstrated that the correlation of Wallis is applicable to the range of values of film thicknesses in the region of low interfacial shear. Subsequent modifications of his theory are present in literature. The range of data and pipe scales for which these modified correlations are efficient, however, is limited. This makes them inaccurate outside the conditions considered for their development. For instance, Aliyu et al. (2017) found that predictions from some selected correlations were unsatisfactory when the internal diameter of the pipe is greater than $100 \mathrm{~mm}$.

Against the backdrop of the utilization of higher viscosity liquids in various industries, most interfacial friction correlations have been developed based on data obtained using air-water systems (Jones and Zuber, 1975; Belt et al., 2009; Kaji and Azzopardi, 2010; Zangana, 2011; 
Aliyu, 2015; Skopich et al., 2015; Aliyu et al., 2017) as well as other liquids of low viscosities, in the order of 1-10 mPa.s (Hori et al., 1978; Fukano and Furukawa, 1998; Holt et al., 1999; Fore et al., 2000). These have been employed in mechanistic models which predict liquid holdup and pressure gradient. The performance of interfacial friction prediction models based on low viscosity is not satisfactory when applied to higher viscosity flows (McNeil and Stuart, 2003) yet in the absence of suitable correlations for higher viscosity flows they are still employed. Lack of experimental data for higher viscosity flows needed for relevant correlation development is responsible for this. The contrary case could improve accuracy of models which would present more realistic field and production conditions which would further translate to improved design of equipment, safety, enhanced production and more profits for investments.

Interfacial shear stress is influenced by the gas-liquid structures and film flow characteristics including heat transfer. There is also strong evidence that interfacial shear stress is strongly influenced by liquid viscosity. Few studies, however, have considered the effect of viscosity on interfacial friction factors (Asali et al., 1985; Fukano and Furukawa, 1998; McNeil and Stuart, 2003). However, these studies have been implemented in small pipes and in addition, their superficial velocity ranges are mostly medium. Authors including Zhang and Sarica $(2011,2012)$ have emphasized the need for new correlations for interfacial among others. Studies focused on interfacial friction factor in medium to large pipes using higher viscosity liquids will provide insight to its character under the flow conditions and further, the combined influence on other flow parameters and facilitate development of much needed correlations for higher viscosity flows in vertical pipes. 


\subsection{Previous works}

Several works which investigate interfacial friction factor for upward annular flow in vertical pipes have been reported in literature. A plethora of correlations which predict this key parameter exist as a result of these efforts. Table 1 summarizes some published correlations. Blasius proposed a model for interfacial friction factor for smooth pipes. The model demonstrated a linear approximation between interfacial friction factor and gas Reynolds number (Aliyu et al., 2017).

One of the early models was also proposed by Wallis (1969). The Wallis correlation for predicting friction factor is the most widely used model. The author treated liquid film interface as form of pipe wall roughness and derived a correlation, which is function of non-dimensional liquid film thickness for prediction of interfacial friction factor (Table 1) (Wallis, 1969). However, the Wallis correlation is valid over a small range of roughness (Pan et al., 2015) and for film thicknesses in the low interfacial shear stress region (Aliyu et al., 2017).

Several modifications have been made to the Wallis correlation with a view to extend its prediction efficiency over data obtained for larger range of film thickness as they became available (Moeck, 1970; Henstock and Hanratty, 1976; Fore et al., 2000; Belt et al., 2009; Pan et al., 2015) and also to improve their predictions. Modifications largely consist of subtle changes in the structure; introduction of new constants (Moeck, 1970) and introduction of dimensionless numbers - gas bulk Reynolds numbers (Asali et al., 1985; Lopes and Dukler, 1986; Fore et al., 2000), Froude numbers (to demonstrate the dependency of interfacial friction on Reynolds numbers and Froude Numbers) (Pan et al., 2015), a viscosity ratio to account for the effect of liquid viscosity (Fukano and Furukawa, 1998) as well as offsets in the $(t / D)$ ratio (Fore et al., 2000). 
Using steam-water mixtures in small pipes, Moeck (1970) proposed a correlation for interfacial friction factor which basically modified a constant in the Wallis equation. Using superficial gas and liquid Reynolds and Froude numbers, Hori et al. (1978) employed a power law relationship to develop a friction factor correlation. The Froude numbers were defined as $F r_{g}=\frac{v_{s g}}{(g D)^{0.5}}, F r_{l}=$ $\frac{v_{s l}}{(g D)^{0.5}}$. Though the Hori et al. (1978) correlation produces good estimates at low values of the interfacial friction factor, substantial over-estimates have been found at high values of interfacial friction factors consistent with low gas flow conditions which generate thick and comparatively rough liquid films. This could be attributed to their experimental conditions which did not cover these regions (Aliyu et al., 2017). Lopes and Dukler (1986) and Fore et al. (2000) established that introduction of a Reynolds number is justified by the occurrence of transition roughness, instead of full roughness. However, no physical basis was offered for this suggestion. Further, the approach required to accurately implement the suggested transition roughness in their correlation is unclear. Fore et al. (2000) opined that Wallis-type correlations and others with Wallis-type dependency on $(t / D)$ fail to sufficiently account for fluctuations in Reynolds number in annular flow. The authors were of the view that such correlations would be more efficient for cases which require minimal dependence on Reynolds number; such as for thin, smooth films (situations where it is justified to conclude that friction factor depends only on dimensionless film thickness)(Aliyu et al., 2017). From their experimental study, they noted that the interfacial friction factor reaches an asymptotic value at sufficiently high gas Reynolds numbers; conditions at which the friction factor becomes solely dependent on the relative film thickness and on this basis proposed a model. The conclusion of the authors, however, was based on a scanty number of data points obtained in the annular flow regime using a pipe of small diameter (Aliyu et al., 2017). 
Observing that some existing correlations inaccurately predicted their database Wongwises and Kongkiatwanitch (2001) also utilized a power law relationship to obtain their interfacial friction factor using the gas Reynolds number and the non-dimensional film thickness $(t / D)$ as correlating parameters. Majority of their data fell within $\pm 25 \%$ of the proposed correlation. The correlation presented by Ambrosini et al. (1991) is a refinement of the Asali et al. (Asali et al., 1985) correlation. The correlation agreed well with the experimental data of Willets (1987) and Asali et al. (1985) within an accuracy of $\pm 30 \%$.

Holt et al. (1999) modified the Ambrosini et al. (1991) correlation and employed it in their model to estimate pressure gradient. Belt et al. (2009) presented a physical approach to predict the interfacial shear-stress, based on the theory on roughness in single-phase turbulent pipe flows. Their results showed close agreement with the theory. Furthermore, they showed that the assumption that sand-grain roughness of the liquid film is proportional to wave height. They found this assertion more effective compared to the regularly utilised assumption that sand-grain roughness of the liquid film is equivalent to four times the mean film thickness (as suggested by Wallis (1969). Finally, they proposed a correlation to determine the interfacial friction factor.

Kumar and Edwards (1996) summarized the deficiencies in existing correlations for predicting interfacial shear stress and proposed a new one. Known as the law of the interface model, it was based on the law of the wall approach in turbulent flows. However, Pan et al. (2015) reports that predictions of the void fraction in their model is less accurate due to the absence of a good mechanistic model for entrainment.

Alves et al. (1991) proposed a mechanistic two-fluid model for annular flow characteristics, including the velocity distributions, liquid entrainment fraction, gas void fraction and pressure gradient. However, the interfacial shear stress model had little relationship with liquid film 
characteristics. His model predictions for a large well database, however, performed better than some existing models including that of Aziz et al. (1972), Hagedorn and Brown (1964), Duns and Ros (1963), Mukherjee and Brill (1985), Beggs and Brill (1973) and Orkiszewski (1967).

Maron et al. (1987) reported a novel approach to predict interfacial friction factor in two-phase wave film flow and established a relationship which directly linked interfacial shear stress and pressure drop to the film waviness and the mobility of the liquid interface. By introducing a momentum recovery coefficient, the authors indirectly accounted for liquid entrainment and deposition processes.

Fukano and Furukawa (1998), using glycerine solutions of up to $10 \mathrm{mPa}$ s, investigated the effect of viscosity on interfacial shear and frictional pressure drop in vertical upwards gas-liquid annular flow and suggested models which predict interfacial friction factor and friction pressure gradient. They observed interfacial structures are strongly dependent on liquid viscosity. They also observed that interfacial shear stresses decrease as viscosity increases when compared under the same mean film thickness. Predictions of their model agreed with their experimental data within an accuracy of $\pm 30 \%$ while that of the pressure gradient matched the experimental data and data obtained from literature within an accuracy of $\pm 20 \%$.

Asali et al. (1985) developed a model for entrainment they interpreted as resulting from a balance between the rate of atomization of the wall film and the rate of deposition of droplets entrained in the gas. From their results, they developed methods to predict friction pressure loss and film height. Wang et al. (2004) investigated the influence of wave height on interfacial friction in annular gasliquid flow and observed that the friction factor decreased less significantly with the decrease of the relative interfacial roughness than that in single-phase flow, which could be attributed to the flat wave shape in annular flow. 
Pan et al. (2015) proposed a model which accounts for interfacial characteristics and the influences of entrainment-deposition processes as well as the formation of gas-eddy. Furthermore, using water (1 mPa s) and liquids of high viscosities (50 mPa s, $200 \mathrm{mPa}$ s and $550 \mathrm{mPa} \mathrm{s}) \mathrm{McNeil}$ and Stuart (2003) investigated the effects of liquid viscosity on upward two-phase flow in vertical pipes. In the first publication, the authors proposed a new model dependent on Froude number (based on gas velocity) to fit their experimental data. The latter work investigated higher viscosity liquid-phase in a nozzle and orifice plate with a vertically upward two-phase flow. Their conclusions indicated that considerable increases in liquid viscosity imposes significant effects on nozzle and orifice plate flows.

Aliyu (2015) and Aliyu et al. (2017) observed that existing correlations could not accurately predict interfacial friction factor for large diameter pipes and proposed two models. The first was used to fit experimental data from large diameter pipes. This model agreed with the experimental data while the second was used to fit experimental data for both large and small diameter pipes was found to be accurate within $\pm 50 \%$.

In this work, characteristics of the annular flow regime using air and higher viscous liquids in a 0.060-m ID pipe are investigated and reported. As a result of a lack of satisfactory predictions for interfacial friction factor, using existing correlations, a correlation for the experimental data is presented. In addition, an ANN model, based on experimental and reported data developed for prediction of interfacial friction factor in both low and higher viscosity data. It is shown in the results and discussions section that predictions of the correlation agree with experimental data. Further, the ANN model accurately predicts $f_{i}$ for both low and higher viscous data. 


\subsection{Reported experimental data}

A total of 127 data points was obtained from literature for this study. These were obtained from 5 sources who utilized a pipe ID ranging from 0.005 to $0.1016 \mathrm{~m}$ for their experiments. Relevant information about the database is presented in Table 2. All data are for macro-scale gas-liquid flows acquired using transparent test sections which facilitated the identification of the flow regime and represent the annular flow regime. A review of reported length-to-diameter $(L / D)$ ratios utilised for the experiments indicate a range of 58 to 92, with the highest presented by Skopich $e t$ al. (2015). Majority of the data were obtained using liquids of low viscosity ( $1-6 \mathrm{mPa}$ s) while the rest range from $100-586 \mathrm{mPa}$. With the exception of the Al-Ruhaimani et al. (2017) data, detailed description of the suitability of the data for this study has been assessed by Aliyu et al. (2017). Al-Ruhaimani et al. (2017) obtained higher viscosity data for annular flow and measured the pressure gradient determine gas void fraction from liquid holdup measurements.

\section{Experimental facility description and data processing}

\subsection{Test rig description}

The experiment was implemented on a test rig capable of inclinations from $0-90^{\circ}$ (Figure 1) at the Gas Lift Innovation Centre, Yangtze University, China. For each experiment, the desired volume of oil was pumped into a mixing tank, and pressurized. After pressure stabilization and measurement, the liquid is mixed with compressed gas and introduced into the test section. The liquid returns to the mixing tank while the air is released into the atmosphere after the gas-liquid mixture has passed through the separator.

The test section (Figure 1) is a pipe of length $10.6 \mathrm{~m}$ and an ID of $0.060 \mathrm{~m}$. The viewing section consists of an acrylic tube with a length of $7 \mathrm{~m}$. Stainless steel pipes of lengths $1.1 \mathrm{~m}$ and $2.5 \mathrm{~m}$ respectively are fixed at each end of the acrylic tube. Pressure, temperature and pressure 
differential sensors, as well as quick closing valves and other devices are installed on the stainlesssteel sections of the pipe. The distance between the two quick closing valves is $9.5 \mathrm{~m}$. The distance between the differential pressure transducers is $8 \mathrm{~m}$. Control of the devices as well as extraction of data is done directly online at the control center. Details of the measuring equipment utilized for the experiment are presented in Table 3. Air constituted the gas phase while oil was used as the liquid phase. The fluid properties used in the experiment are presented in Table 4.

\subsection{Fluid properties for the experiment}

Compressed air and white oil constituted the gas and liquid phases respectively. The oil density was $854 \mathrm{~kg} / \mathrm{m}^{3}$ at $20^{\circ} \mathrm{C}$ with a surface tension of $0.0287 \mathrm{~N} / \mathrm{m}$. Variations in density and surface tension of the oil with temperature was small enough to assume it is negligible. Increase in viscosity was achieved by decreasing temperature. The behaviour of the oil viscosity versus temperature is as shown in Figure 2a. The oil utilised was non-Newtonian in nature and its viscosity was measured using a Brookfield Viscometer (DV-3T) while ZNN-D6B six-speed rotary viscometer (Qingdao Shande Petroleum Instrument, China) was used to obtain the shear stress and shear strain rheological data shown in the plot (Figure 2b)

\subsection{Experimental procedure and measurement}

For this study, a constant liquid flow rate was maintained, while the gas flow rate is adjusted. When the system was deemed steady (approximately 15 minutes from the start of the experiment), the experimental flow pattern was observed and recorded. Except for liquid holdup, all other experimental data was recorded every 5 seconds for 3 minutes, and finally the average value of each measurement parameter was obtained. Each complete test took approximately 30 minutes depending on the time required to reach steady-state. After the data recording was completed, the quick closing valves (2 Limit Switch Box APL-210 mechanical actuators which can be actuated 
simultaneously with a single switch) were closed trapping fluids flowing in the test section. The quick closing valves have a response time is $0.3-0.5 \mathrm{~s}$. Liquid holdups are measured by using a $9.5 \mathrm{~m}$ longitudinal pipe section. For accurate measurement of liquid holdup, the trapped air-oil mixture was allowed to settle for 5-10 minutes to facilitate draining of the liquid into a measuring cylinder. Liquid holdup was estimated by calculating the volume of the liquid and dividing it by the volume of pipe-section. Flow patterns were visualized directly and also observed using a Canon Xtra NX4-S1 high-speed camera capable with a pixel resolution of resolution of 1024x1024 up to 3000 frames per second (fps). The maximum frame rate is $50,000 \mathrm{fps}$ with a reduced resolution. Videos and pictures of the flow pattern were obtained and used for analysis during the study. The range of measurements taken during the experiments is presented in Table 5.

For these experiments, the camera was located at $\mathrm{L} / \mathrm{D}=133$, at this location, the flow is considered to be fully developed based on a survey of similar experiments in the literature. Fully developed annular flow pattern in vertical pipes has been observed at L/D values lower than ours by a number of researchers including Wongwises and Kongkiatwanitch (2001) (L/D = 41), Aliyu et al. (2017) $(\mathrm{L} / \mathrm{D}=46)$, Fore and Dukler (1995) (L/D = 69), Zangana (2011) (L/D = 66), Skopich et al. (2015) $(\mathrm{L} / \mathrm{D}=59-92)$, and Van der Meulen (2012) (L/D = 87). Shearer and Nedderman (1965) conducted some experiments with an $\mathrm{L} / \mathrm{D}=133$. It can be assumed, therefore, that the selected $\mathrm{L} / \mathrm{D}$ ratio represents a sufficient flow development length.

\subsection{Data processing}

In this section, all mathematical expressions used to derive values for parameters used for this study are presented and discussed. Experimental data is used to estimate the required parameters. 


\subsubsection{Entrained droplet fraction}

For this study, the entrained droplet fraction was estimated with the Aliyu et al. (2017) correlation (Eq. 1) developed based on a large data set which accounts for a wide variation of flow conditions and is suitable for application to pipe diameters from 5-127 mm:

$$
e= \begin{cases}\frac{1.00 \times 10^{-2} W e^{0.33} R e_{l}^{0.27}}{1+\left(1.00 \times 10^{-2} W e^{0.33} R e_{l}^{0.27}\right)} & \text { for } v_{s g}>40 \mathrm{~m} / \mathrm{s} \\ \frac{1.25 \times 10^{-3} W e^{0.15} R e_{g}^{0.20} R e_{l}^{0.23}}{1+\left(1.25 \times 10^{-3} W e^{0.15} R e_{g}^{0.20} R e_{l}^{0.23}\right)} & \text { for } v_{s g} \leq 40 \mathrm{~m} / \mathrm{s}\end{cases}
$$

\subsubsection{Estimation of interfacial friction factor values from experimental measurements}

For the current investigation, pressure drop, liquid holdup, liquid film thickness and velocity measurements obtained are be used to characterize the annular flow region. Subsequently, the data is used to determine values for the interfacial friction factor. For fully developed two-phase annular flow, the typical definition for interfacial friction factor is given by Eq. (2):

$f_{i}=\frac{2 \tau_{i}}{\rho_{g} v_{s g}^{2}}$

However, several authors (Fore and Dukler, 1995; Fore et al., 2000; Wongwises and Kongkiatwanitch, 2001; Aliyu et al., 2017) indicate that for many cases of annular flow, liquid droplets become entrained in the gas core significantly affecting its density. The liquid droplet entrainment - deposition process, present in gas-liquid annular upward flows account for $20 \%$ of the pressure gradient (Fore and Dukler, 1995; Fore et al., 2000). To reflect the effect of entrainment, Eq. (3) is modified to become:

$$
f_{i}=\frac{2 \tau_{i}}{\rho_{C} v_{C}^{2}}
$$

The subscript c represents the core region. From the equation, it is clear that the core density and core velocity must be determined. 


\subsubsection{Core velocity}

Determination of the core density $\rho_{c}$ requires values of the liquid film velocity which were estimated. The core velocity is estimated by writing a mass balance of the gas input, which yields the relations for the mean velocity for the gas core (Vieira et al., 2015) as follows Equation (4):

$v_{C}=\frac{\left(v_{s g}+U_{s l} e\right) D^{2}}{(D-2 t)^{2}}$

where $t$ is the liquid film thickness was estimated using Eq. (5):

$t=\frac{D}{2}(1-\sqrt{\varepsilon})$

where $\varepsilon$ is the gas void fraction obtained from measured liquid holdup values. Equation (5) assumes that the liquid film thickness is circumferentially uniform around the pipe. This method was employed by several authors including Fukano and Furukawa (1998), Alamu (2010) and Kaji and Azzopardi (2010).

\subsubsection{Core density}

The density of the gas core $\rho_{C}$ interspersed with entrained liquid droplets, utilized in Equation (6) is determined using by finding the arithmetic mean of the liquid droplet densities and the pure gas as follows:

$\rho_{C}=\left(1-\varepsilon_{C}\right) \rho_{l}+\varepsilon_{C} \rho_{g}$

where $\varepsilon_{C}$ (Fig. 1) is the gas void fraction (of the core) estimated as:

$\varepsilon_{C}=\frac{\varepsilon}{\varepsilon+\gamma(1-\varepsilon)}$

$\varepsilon$ is the cross-sectionally averaged void fraction and $\gamma$ is the droplet holdup.

Methods to obtain gas void fraction data are adequately detailed by Wu et al. (2017). Gas void fraction is either obtained directly using cross-sectionally averaged data or from liquid holdup data. 
There is a clear distinction between cross-sectionally averaged- and volumetric gas void fraction. Cross-sectionally averaged gas void fraction can be obtained using advanced measuring devices including Wire Mesh Sensor (WMS) and Electrical Capacitance Tomography (ECT) while the volumetric gas void fraction is extracted from liquid holdup data using quick closing values (QCVs).

QCVs have been employed to measure liquid holdup (gas void fraction) (Bhagwat and Ghajar, 2012; Cioncolini and Thome, 2012; Xue et al., 2016) for several studies reported on gas void fraction. Further, some reports indicate that there is very little difference between gas void fraction values obtained using different methods. For instance, Viera et al. (2015) compared the liquid holdup results obtained by Yuan (2011) and Guner (2012) using QCVs for $v_{s g}$ values ranging from 10 to $40 \mathrm{~m} / \mathrm{s}$ and his experiments using WMS, the same flow conditions as well as liquid viscosities from 1 to $40 \mathrm{mPa}$ s. Their results showed that similar results could be obtained from both methods. For this study, values of gas void fraction were obtained using QCVs.

Adopting the definition of the entrained droplet fraction $e$ which is the ratio of the entrained liquid droplet mass flow $\dot{m}_{d}$ rate to that of the total mass flow rate $\dot{m}_{l}$ an expression for droplet holdup $\gamma$ can be obtained as:

$e=\frac{m_{d}}{\dot{m}_{l}}=\frac{\rho_{l} v_{d} A_{d}}{\rho_{l} v_{s l} A}=\frac{v_{d} A_{d}}{v_{s l} A}$

If it is assumed that the phase slip between the droplet and the (carrier) gas is ignored, then the droplets will travel at the same velocity as the carrier gas; therefore $v_{d}=v_{G}$. Eq. (8) will now become:

$e=\frac{v_{G} A_{d}}{v_{s l} A}=\frac{\frac{v_{s g}}{\varepsilon} A_{d}}{v_{s l} A}$ 
Substitution of the relation for the cross-sectional area $A_{d}$ occupied by the droplets based on phase splits as illustrated in Fig. 2, Eq. (9) can be re-written as:

$e=\frac{v_{s g}}{v_{s l}} \frac{\gamma(1-\varepsilon)}{\varepsilon}$

Gas quality is a function of gas and liquid densities and gas and liquid superficial velocities and can be defined as:

$x=\frac{\rho_{g} v_{s g}}{\left(\rho_{g} v_{s g}+\rho_{l} v_{s l}\right)}$

Re-arrangement of Eq. (11) yields $\frac{v_{s g}}{v_{s l}}=\frac{x \rho_{l}}{(1-x) \rho_{g}}$ which can be substituted into Eq. (10) to give the following:

$e=\frac{x \rho_{l}}{(1-x) \rho_{g}} \frac{\gamma(1-\varepsilon)}{\varepsilon}$

A final re-arrangement provides the following expression for droplet holdup for application in Eq.

(13) is given by:

$\gamma=e \frac{\varepsilon}{1-\varepsilon} \frac{1-x}{x} \frac{\rho_{g}}{\rho_{l}}$

\subsubsection{Interfacial shear stress}

The interfacial shear stress $\tau_{i}$ is derived from a momentum balance based on the gas core in the axial direction of the flow (Figure 3). The assumptions made include fully developed flow at steady state and equilibrium where respective rates of droplet entrainment and deposition are equal (detailed derivation is found in Fore et al. (2000) and Wongwises and Kong (2001)). Therefore,

$\tau_{i}=\frac{D-2 t}{4}\left(-\frac{d P}{d z}-\rho_{C} g\right)$

where $g$ represents gravitational acceleration. 
where $-\frac{d P}{d z}$ is the measured total pressure gradient. Using Eq. (1-14) the interfacial friction factor can be calculated. This approach differs slightly from that of Fore et al. (2000) in that the authors could directly measure the parameters in their final equation. The current approach better suits the experimental data obtained.

\section{Experimental results and discussion}

\subsection{Visual observations and flow regime identification}

For all flow conditions in the study, slug (Figure 5a-d), churn and annular (Figure 5e-h) flow were observed at all liquid viscosities. The annular flow regime was characterized by liquid film flowing upward in the inner periphery of the pipe. The liquid film flowed along the full length of the pipe. Entrained oil droplets could be observed flowing upward within the gas core at the center of the pipe.

At low phase velocities, a comparatively thick liquid film was observed at all viscosities. The thickness of the liquid film appeared to reduce as gas velocities was increased. Liquid film thickness continued to reduce even when liquid velocity was increased. This was the trend for all viscosities. Liquid velocities contributed to the total phase momentum driving reduction of the liquid film. This phenomenon is consistent with the findings Fukano and Furukawa (1998) who concluded, from their studies, that liquid film thickness decreases independent of liquid viscosity and velocity. Further, at fixed phase velocities, liquid film thickness increased as liquid viscosity increased. It was found that liquid film appeared thickest at $330 \mathrm{mPa}$ s at all superficial velocities.

Ripples were also observed on the surface of the liquid films at different flow conditions for different liquid viscosities. Ripples appeared gentle at first and increased in roughness as gas and liquid velocities increased. The surface of the liquid film appeared comparatively smoother at 
higher gas velocities. For instance, at $200 \mathrm{mPa}$, gentle ripples were observed at $v_{s l}$ and $v_{s g}$ values of 0.03 and $12.78 \mathrm{~m} / \mathrm{s}$ respectively. Figure 5 shows ripples on the surface of the liquid film at different superficial phase velocities. It can be observed that ripples exist on the surface of the liquid film at $v_{s l}$ value of $0.05 \mathrm{~m} / \mathrm{s}$ and $v_{s g}$ values of 34.38 and $39.29 \mathrm{~m} / \mathrm{s}$ respectively making the surface rough. Slight changes in superficial gas velocity makes no impact on the ripples (Figure 5a and 5b). An increase in superficial liquid velocity does not seem to yield any changes (Figure 5c), the observed phenomenon remains the same. At higher superficial gas velocity (Figure 5d), however, a thinner liquid film is observed. In addition, comparatively gentle ripples are observed on the surface of the liquid film. Much larger ripples were observed at liquid viscosity of $330 \mathrm{mPa}$ s at lower gas velocities. Fukano and Furukawa (1998) also reported observing ripples on the liquid film surface for all viscosities they considered. They characterized this phenomenon as ripple flow. In addition, the appearance of the wavy surface appeared different for different viscosities even under the same flow conditions. Similar observations were reported by Fukano and Furukawa (1998). The observations agree with their suggestion that interfacial friction factor, which is directly linked to wave characteristics, significantly affected by liquid viscosity.

\subsection{Comparison with flow pattern map}

The flow pattern for the various liquid viscosities was observed directly through the acrylic viewing section of the test pipe. Data obtained was superimposed on the Shell flow pattern map (2007) (Pinto del Corral, 2014; Aliyu et al., 2017) and the flow pattern map of Taitel et al (1980) respectively (Figure 5).

Created by the Shell Company (Pinto del Corral, 2014; Aliyu et al., 2017) for transport (charge and discharge) of combustibles, the Shell map flow pattern map is generalized by using the superficial gas and liquid Froude numbers respectively based on the feed pipe velocity and 
diameter. For the shell flow pattern map, the densimetric Froude numbers employed are defined as follows:

$F r_{g}=v_{s g}\left(\frac{\rho_{g}}{\left(\rho_{l}-\rho_{g}\right) g D}\right)^{0.5}, F r_{l}=v_{s l}\left(\frac{\rho_{l}}{\left(\rho_{l}-\rho_{g}\right) g D}\right)^{0.5}$

It is found that the flow pattern map agrees very well with the experimental data. This could be attributed to the closeness to of some of the phase properties used in its development $\left(\rho_{l}=\right.$ $860 \mathrm{~kg} / \mathrm{m}^{3}, \mu_{g}=1.6 \times 10^{-4} \mathrm{~Pa} . \mathrm{s}, \sigma=0.03 \mathrm{~N} / \mathrm{m}$ ) to the experimental fluid properties. Though the flow pattern map was developed with a very large diameter $(500 \mathrm{~mm})$, this does not seem to provide any limitation.

The Taitel et al. (1980) flow pattern map was developed by employing different transition criteria which utilized analytical relationships for the force balance between gravity and drag forces acting at the onset of annular flow. The related theories were validated with data obtained from a 50-mm ID pipe. It is found that the flow regime map agrees with the experimental observations.

Schmidt et al. (2008) reported a shift towards low superficial gas velocities on the Taitel et al (1980) flow pattern map when a higher viscosity liquid was compared to water. He also reported that Taitel et al. (1980) had reported a similar observation for experimental data which utilized natural gas and crude oil. The reported phenomenon was not observed in this study.

It is observed that the Shell flow pattern map is unable to detect and characterize data points indicating transition to annular flow (Figure 6a), all points are classified as annular flow. On the other hand, the Taitel et al. (1980) flow pattern map is able to identify data points close to the transition and also within the annular flow regime (Figure 6b). 


\subsection{Liquid Holdup}

Generally, it is observed that at all viscosities, liquid holdup decreases as superficial gas velocity increases as shown in Figure 7. The error bars were determined as the standard deviation of triplicate measurements as all experiments were carried out three times for the purpose of determining uncertainty. The decrease is sharp at lower superficial gas velocities and asymptotic at higher superficial gas velocities $\left(v_{s g}>40 \mathrm{~m} / \mathrm{s}\right)$ for liquid viscosities of 100,150 and $200 \mathrm{mPa}$ s respectively. Again, it is found that liquid holdup decreases as superficial liquid velocity increases. However, the decreases do not appear to be significant. This can be attributed to the fact that increase in quantity and the velocity of the liquid is not enough to counter the effects of the high gas velocity. This makes the contribution of the superficial liquid velocity rather insignificant.

In addition, the results indicate that at fixed superficial air velocities values, increase in liquid viscosity increases liquid holdup. Increased liquid viscosity results in increased shear stresses which translates into increased liquid accumulation at higher liquid viscosities (Al-Ruhaimani et al., 2017). Increase in liquid holdup can also be attributed to liquid droplet entrainment behaviour with respect to liquid viscosity. Liquid droplet entrainment decreases with increasing liquid viscosity (Al-Ruhaimani et al., 2017).

\subsection{Pressure Drop}

Pressure drop is found to increase as superficial gas velocity increases. It appears the churn-annular transition occurs at superficial gas velocity value of $28 \mathrm{~m} / \mathrm{s}$. Below this value gradual increases in values of pressure drop are observed in for liquid viscosities of 100 and $200 \mathrm{mPa}$ s respectively. Data points for 150 and $330 \mathrm{mPa}$ s show decrease in pressure drop as superficial gas velocity increases. Increasing pressure drop at high viscosities can be attributed to increase in friction at the gas-liquid interface. The liquid formed at the gas-liquid interface generates an interfacial 
friction which is normally higher than the gas-wall friction, especially when the gas-liquid interface becomes wavy. Further, increase in pressure drop could be influenced by increments in the density of the gas phase as a result of entrained liquid. Finally, at fixed liquid superficial velocity, as gas superficial velocity increases slip within the gas-liquid interface increases. This phenomenon leads to a higher interfacial shear and corresponding increase in the total pressuregradient (Alamu, 2010).

The effect of superficial liquid velocity on pressure drop is not apparent (Figure 8). Perhaps, as earlier explained, the $v_{s l}$ values are too small to make any significant difference. At fixed superficial phase velocities, however, it is found that increase in liquid viscosity increases pressure drop. Increasing liquid viscosity results in increased frictional pressure drop during flow as well as increasing liquid holdup which also translates to increased gravitational pressure gradient. Increases in the two components naturally increases the total pressure drop.

\subsection{Liquid film thickness}

The liquid film thickness was estimated from the liquid holdup data which was obtained using quick closing valves. Gas void fraction was first calculated from the liquid holdup data using the expression:

$\varepsilon=1-H_{l}$

In vertical annular flow, it is assumed the liquid flows unfirmly along the pipe walls during upward flows. Furthermore, coupled with the case where little of no liquid entrainment occurs in the gas core, as was the case in this study, the liquid film thickness can be estimated using the geometrical expression (Eq. 5): 
$t=\frac{D}{2}(1-\sqrt{\varepsilon})$

This method has been used previously by other authors (Kaji and Azzopardi, 2010; and Almabrok et al. (2016) for the calculation of film thickness from void fraction.

The variation of liquid film thickness for the liquid viscosities $(100 \mathrm{mPa} \mathrm{s}, 150 \mathrm{mPa} \mathrm{s}, 200 \mathrm{mPa} \mathrm{s}$, $330 \mathrm{mPa} \mathrm{s}$ ) against superficial gas velocity is shown in Figure 9. Results from investigation the behaviour of liquid film thickness indicate that it reduces as superficial gas velocity increases. For all superficial liquid velocity values, at all viscosities, liquid film thickness is observed to decrease asymptotically. The decrease is rapid at low superficial gas velocities. Liquid film thickness is maximum at liquid viscosity of $330 \mathrm{mPa}$. This is because it presents the greatest resistance to the flow conditions (reducing liquid droplet entrainment and increasing liquid holdup in the process). Liquid film thickness values are highest at liquid viscosity of $330 \mathrm{mPa}$ s and decrease with decreasing liquid viscosity. The observation of the behaviour of liquid film thickness when subjected to varied gas velocity is similar to reports by authors who utilized air-water mixtures (Wongwises and Kongkiatwanitch, 2001; Aliyu et al., 2016; Aliyu et al., 2017; Matsuyama et al., 2017). Similar findings have also been reported by Fukano and Furukawa (1998) and Kaji and Azzopardi (2010) who used low viscosity liquids for their experiments.

\subsection{Error propagation}

The uncertainty of the friction factor was estimated from the experimental data. It is vital to estimate the error in the interfacial friction factor calculated from experimental measurements. In order to do this, we substitute Eq. (6) into Equation (5).

$$
\begin{aligned}
f_{i} & =\frac{2 \tau_{i}}{\rho_{g} v_{s g}^{2}} \\
\tau_{i} & =\left(-\frac{d P}{d z}+\rho_{c} g\right)\left(\frac{D-2 t}{4}\right)
\end{aligned}
$$


This yields the relationship for calculating interfacial friction factor in terms of all the measured experimental quantities of pressure gradient, liquid film thickness and core density (which is a function of the liquid film velocity)

$f_{i}=\frac{2\left(-\frac{d P}{d z}+\rho_{c} g\right)(D-2 t)}{2 \rho_{g} v_{s g}^{2}}$

The dominant quantities in the uncertainty estimation from the equations above are $\frac{d P}{d z}, \rho_{c}$ and $\mathrm{t}$. Assuming these variables are independent, the uncertainty in $f_{i}$ caused by the random errors in measurements can be given as a relative error expressed as follows:

$\frac{\delta f_{i}}{f_{i}}=\sqrt{\frac{(\delta A)^{2}+\left(g \delta \rho_{c}\right)^{2}}{\left(A+g \rho_{c}\right)^{2}}+\left(\frac{2 \delta t}{D-2 t}\right)^{2}}$

where $A=\frac{d P}{d z}$ and the $\delta$ represents uncertainties in the respective quantities in bracket. For pressure gradient measurement, the full-scale uncertainty is given as $\delta A= \pm 0.1 \%$. For the film thickness, since it was determined from the liquid holdup via the void fraction, i.e.

$t=\frac{D}{2}(1-\sqrt{\varepsilon})$

then,

$\frac{\delta t}{t}=\frac{\frac{1}{2} \delta \varepsilon}{(1-\sqrt{\varepsilon})}=\frac{\delta H_{l}}{2\left(1-\sqrt{1-H_{l}}\right)}$

The uncertainty in the liquid holdup measurements was estimated to be 0.1 . The uncertainty in the gas core density is not readily available since it is a derived quantity obtained from the liquid film velocity. Therefore, the uncertainty in the gas core $\rho_{c}$ is deduced from its definition in Eq. (7).

$\rho_{c}=\left(1-\varepsilon_{c}\right) \rho_{l}+\varepsilon_{c} \rho_{g}$

Details of its derivation are presented here. When Eqs. (1), (2) and (10) are substituted into Eq. (7) and simplified, it yields an explicit expression in terms of $v_{l f}$ :

$\rho_{c}=\rho_{l}-\frac{\varepsilon\left(\rho_{l}-\rho_{g}\right)}{\varepsilon+\left(1-\frac{\rho_{l} l_{l}^{A}{ }_{l f}}{W_{t}}\right)\left(\frac{\varepsilon}{(1-\varepsilon)}\right)\left(\frac{1-x}{x}\right)\left(\frac{\rho_{g}}{\rho_{l}}\right)}$

But 
$\delta\left(\rho_{c}\right)=\frac{\partial \rho_{c}}{\partial v_{l f}} \delta\left(v_{l f}\right)$

where $\frac{\partial \rho_{c}}{\partial v_{l f}}$ is obtained by differentiating Eq. (17) and re-arranging, we can obtain the following expression:

$\frac{\partial \rho_{c}}{\partial v_{l f}}=\frac{\varepsilon\left(\rho_{l}-\rho_{g}\right)\left(\frac{\varepsilon}{(1-\varepsilon)}\right)\left(\frac{1-x}{x}\right)\left(\frac{\rho_{g}}{\rho_{l}}\right)\left(1-\frac{\rho_{l} v_{l f} A_{l f}}{W_{t}}\right)}{\left[\varepsilon+\left(1-\frac{\rho_{l} v_{l l} A_{l f}}{W_{t}}\right)\left(\frac{\varepsilon}{(1-\varepsilon)}\right)\left(\frac{1-x}{x}\right)\left(\frac{\rho g}{\rho_{l}}\right)\right]^{2}}$

Error in film velocity $\delta\left(v_{l f}\right)$ is obtained by deriving an expression for liquid film velocity by carrying out a mass balance of the flowing liquid and simplifying:

$v_{l f}=\frac{v_{s l} D^{2}(1-e)}{4 t(D-2 t)}$

from which we can write the expression for uncertainty in $v_{l f}$ :

$\left(\frac{\delta v_{l f}}{v_{l f}}\right)^{2}=\left(\frac{\delta e}{1-e}\right)^{2}+\left(\frac{4 \delta t}{4 t}\right)^{2}+\left(\frac{2 \delta t}{D-2 t}\right)^{2}$

giving:

$\delta v_{l f}=v_{l f} \sqrt{\left(\frac{\delta e}{1-e}\right)^{2}+\left(\frac{2 \delta t}{D-2 t}\right)^{2}+\left(\frac{4 \delta t}{4 t}\right)^{2}}$

The error in the entrained droplet fraction $\delta e$ was not readily available since we did not measure this quantity. However, $10 \%$ relative error was used based on the median values reported by (Aliyu et al., 2017). Finally, the percentage error in for each $f_{i}$ from the experimental conditions is expressed as:

$\% \operatorname{Err}\left(f_{i}\right)=\frac{\delta f_{i}}{f_{i}} \times 100 \%$

Figure 13 shows the uncertainty values in $f_{i}$ calculated using Equations (15)-(23). As can be seen, most of the errors are around $\pm 10 \%$. Compared with percentage errors calculated by (Aliyu et al., 2016), where mean errors of $\pm 7.5 \%$ were reported, our values are not far away and the differences may be attributed to the fact measurements for the entrained droplet fraction were available in their study. 


\subsection{Comparison of experimental interfacial friction factor and correlations}

The interfacial friction factor, $f_{i}$ is calculated from experimental data using Equation (3). Like the liquid film thickness, the results indicate that $f_{i}$ decreases asymptotically with increase in superficial gas velocity independent of superficial liquid velocity.

The observation is well explained by Equation (3). There is a direct relationship between pressure drop (or pressure gradient) and interfacial frication factor. In this study, therefore, the reduction in the value of interfacial friction factor, can be attributed to a reduction in the pressure drop whose behaviour has been explained in section 3.4. The trend of the interfacial friction factor with superficial gas velocity can also be explained using the relationship defined in Equation 2 as well as gas velocity within the core (Equation 3). In this study, it is observed that, like the studies of Fukano and Furukawa (1998), gas velocity influences interfacial friction factor. High gas velocities yield low $f_{i}$ values. The values of $f_{i}$ in this study, however, are comparatively higher than theirs.

Here, the current experimental data is compared with 16 existing models developed for the prediction of interfacial friction factor. Summarized information about the correlations are summarized in Table 6. A pictorial assessment is presented in Figure 10.

The Fore et al. (2000) correlation presents the best performance when evaluated with the experimental data (Figure 10). The correlation's underprediction of the experimental data occurs at low values of non-dimensional film thickness. The underprediction (APE=15.20) and prediction errors $(\mathrm{AAPE}=24.77)$ of this correlation are found to be reasonable. The second-best performance is presented by the Holt et al. (1999) correlation with AAPE value of 28.36 and APE value of 23.53. The Holt et al. (1999) correlation exhibits a similar performance as that of Blasius Aliyu et al., 2017) which occupies the third-best position with AAPE value of 29.16 and APE value of 
24.87. Both correlations underpredict the experimental data within reasonable limits at higher values of non-dimensional film thickness. The predictions of Belt et al. (2009) are found to be better than (AAPE, APE=41.49) those of Ambrosini et al. (1991), Akagawa (Matsuyama et al., 2017), Wongwises and Kongkiatwanitch (Wongwises and Kongkiatwanitch, 2001), Fukano et al.(1985), Fukano and Furukawa (1998), and Aliyu et al. (2016) (listed in order of increasing prediction errors and underprediction). The correlations of Matsuyama et al. (2017), Moeck (1970), Wallis (1969) and Aliyu et al. (2017) (listed in order of increasing prediction errors) predict the experimental data with AAPE values of more than $100 \%$ percent with corresponding high overpredictions (Figure 10).

Fore et al. (2000) employed a Wallis-type correlation developed based on nitrogen-water mixtures. Their modification lies in the offset in the (t/D) ratio. Their model was based on the observation that the trend of values of the interfacial friction factor become asymptotic at sufficiently high Reynolds numbers; a condition at which the friction factor becomes solely reliant on the relative film thickness. Perhaps, similar conditions found in this experiment, hence its satisfactory predictions. The correlation presented by Holt et al. (1999) was developed using smaller pipes and conduits than was employed in the study. However, the correlation accounts for both fluid and gas properties. This could be the explanation for its performance. The Blasius correlation was developed for and is limited to single-phase turbulent flows in pipes with hydraulically smooth wall (Matsuyama et al., 2017). This correlation is a function of only $R e_{g}$, indicating that interfacial friction factor depends solely on superficial gas velocity and is valid for $R e_{g}$ values of up to $10^{5}$ which also correspond to thin liquid films. The experimental conditions fall within this condition and therefore the predictions of the correlation are not surprising. Conditions for this two-phase flow study differ from the experimental condition employed by Blasius. The correlation is limited 
to thin liquid film thicknesses and may be accurately predicting the experimental data at this condition but unsatisfactorily when the liquid film thickness begins to increase. This is an indication that only one parameter, $R e_{g}$, is inadequate to handle the physical phenomenon and hence accurately predict the interfacial friction factor.

The theoretical correlation presented by Wallis (1969) overpredicts the experimental data. Its behaviour can be attributed to its efficiency over only a small range of roughness and film thicknesses in the low interfacial shear stress range. The Moeck (1970) correlation exhibits high disagreement with the experimental data characterized by high prediction errors as well as overprediction. The correlation was developed using steam-water data and a smaller pipe diameter. Differences in fluid properties and pipe dimensions may be responsible for its unsatisfactory performance.

The Akagawa et al. (1974) correlation (Matsuyama et al., 2017) is a function of superficial gas and liquid Reynolds numbers. The correlation generally underpredicts the experimental data, perhaps indicating the need for more parameters. The Hori et al. (1978) correlation accounts for both gas and liquid properties (including liquid viscosities). However, its predictions are not close enough, perhaps due to differences in liquid viscosities and pipe diameters both of which are smaller than was employed for the current study. Fukano and Furukawa (1998), using glycerine solutions of up to $10 \mathrm{mPa}$ s. Their correlation account for viscosity and liquid film thickness. The inability of the correlation could be attributed to differences in liquid viscosity. Though the Ambrosini et al. (1991) correlation accounts for a wide range of fluid properties, its ability to predict the experimental data can be attributed to the utilization of smaller pipes. The correlation of Fukano et al. (1985) accounts for both liquid and gas physical and flow properties. Its limitation 
lies in its inability to compensate for differences in liquid viscosities and conduits utilized (the authors employed a rectangular duct for their study).

Wongwises and Kongkiatwanitch (2001) accounted for gas properties and liquid film thickness in this correlation. However, its inefficiency (AAPE, APE=73.96) could be emanating from the fact that it was developed from air-water mixtures and small pipes. The liquid viscosity and pipe dimensions are much lower than was employed in the study. The Belt et al. (2009) improved the correlation of Wallis by relating the roughness of the liquid film to wave height. Based on this this theory they developed a Wallis-type correlation. From the analysis, their theory seems to agree with the experimental data. However, the correlation is a function of non-dimensional liquid film thickness. This could be the source of limitation to a higher performance. The Matsuyama et al. (2017) correlation, being a modification of the Fore et al. (2000) correlation also integrates the surface tension of liquids, superficial air velocity (in the form of superficial Reynolds number) and liquid film thickness (represented as non-dimensionless liquid film thickness). However, its inability to account for liquid viscosity and utilization of a small pipe diameter could be the limitation to its accuracy.

The Aliyu et al. (2017) correlation utilized data from upward flows, air-water mixtures and wide range of pipe diameters. However, its prediction errors are high and the correlation is also found to highly overpredict the experimental data, possibly due to its inability to account for liquid viscosity. On the other hand, the Aliyu et al. (2016) correlation for downward flows underpredicts the experimental data for the same reasons. 


\section{Correlation of experimental data}

From the fore-going discussion it has been shown that only a few considered existing correlations were able to satisfactorily predict the experimental interfacial fraction factors for the higher viscosity experimental data. However, since more accurate predictions are required, development of an accurate correlation to predict the experimental data is essential. Unlike the classic correlations which is a function of only the dimensionless film thickness, it is also important to match the friction factor data such that it accounts for other parameters which describe its behaviour. To achieve this several correlating parameters previously used in literature were considered. Suitable correlating parameters including superficial gas Reynolds number $R e_{g}$, film thickness non-dimensionalised by the friction velocity $t_{g}^{+}$, non-dimensional liquid film thickness, $t / D$, superficial gas velocity Froude number, $F r_{g}$ and liquid viscosity number, $N_{f}$ were used for this correlation.

Asali et al. (1985) and Ambrosini et al. (1991) presented correlations for interfacial friction factor which are functions of film thickness $t_{g}^{+}$non-dimensionalised by the friction velocity. Solutions to their correlations required an iterative process since they were implicit functions. Their correlations provide good predictions in regions of higher shear, where liquid films are smoother and thinner. The authors employed similar databases consisting of data obtained using pipes with ID of $10-42 \mathrm{~mm}$ and fluid combinations of helium and hydrocarbons/glycerine mixtures for their correlation development. A direct relationship exists between $t_{g}^{+}$and interfacial friction factor. Increase in the values of $t_{g}^{+}$yields corresponding increasing values of $f_{i} / f_{g}$. Further, $t_{g}^{+}$accounts for the important parameters which adequately describe the fluid characteristics and is also found to collapse the interfacial friction factor data well for all viscosities (Figure 11a). 
The film thickness non-dimensionalised by the friction velocity is given by Equation 15:

$t_{g}^{+}=\frac{t}{v_{g}}\left(\frac{\tau_{i}}{\rho_{g}}\right)^{0.5}$

where $t, v_{g}, \tau_{i}, \rho_{g}$ represent the liquid film thickness, kinematic viscosity of the gas, interfacial shear stress and density of the gas respectively. The film thickness, t, was estimated using Eq. (5).

Reports from several experimental studies indicate an inverse relationship between interfacial friction factor and gas Reynolds number which is similar to the turbulent flow region of the Moody Chart for single-phase flow. Similar findings are observed for the data obtained for this study for all viscosities (Figure 11b). It is further observed that the friction factor decreases as the gas Reynolds number increases for all liquid viscosities. At lower gas Reynolds numbers, a sharp reduction in the value of interfacial friction value is observed while at higher values, it becomes asymptotic; further increase in gas Reynolds number exerts no effect on the friction factor. Further, increase in viscosity translates to a corresponding increase in friction factor values. The gas Reynolds number used for this work is utilizes the superficial gas velocity and pipe diameter given as:

$R e_{g}=\frac{\rho_{g} v_{s g} D}{\mu_{g}}$

The combined dimensionless group consisting of $t_{g}^{+} R e_{g}$ has been previous been found to collapse the $f_{i} / f_{g}$ data of Asali et al. (1985), Hajiloo et al. (2001) and Aliyu et al. (2016) very well. In this study, it is observed that it also successfully collapses the data for all viscosities.

The effect of liquid viscosity on $f_{i} / f_{g}$ when it is varied with values of $t_{g}^{+}$appears negligible since no systematic differences are observed (Figure 11a). On the other hand, for $\operatorname{Re}_{g}<1 \times 10^{5}$ the 
effect of viscosity is evident. Beyond $R e_{g}>1 \times 10^{5}$, however, the effect of viscosity diminishes indicating that as gas velocity increases liquid viscosity becomes less significant.

Reported studies show that $f_{i}$ increases as $t / D$ increases. A similar finding is observed for the current study. The dimensionless film thickness has the capacity to reveal the behaviour of the interfacial frication factor at all regions within the annular flow regime. Therefore, it is an important parameter for correlating interfacial fraction factor data.

The superficial gas Froude number, expressed by Equation (17) is also included because it expresses a relationship between the forces of inertia experienced by the pressure-driven gas-liquid flow and the opposing gravitational force. This relationship gains importance at high-velocity gas flow conditions in vertical upward annular two-phase flows, as is the case for this study where gas Froude number, $F r_{g}$ was calculated as:

$F r_{g}=\frac{v_{s g}}{(g D)^{0.5}}$

When the forces of inertia become dominant, resulting in $F r_{g}>1$, the tendency for downward flow of the liquid film is overcome by inertia from the gas flow. This condition is termed supercritical flow. $F r_{g} \approx 1$ denotes the critical gas Froude number at the flow reversal point. If $F r_{g}<1$, occurrence of annular flow is not considered; churn flow remains as a result of competition of the two opposing forces. Including the gas Froude number, therefore, is consistent with annular flow phenomenon.

Both $t / D$ and $F r_{g}$ are functions of pipe diameter and thus the dimensionless group is an even stronger function of pipe diameter. When utilized, Hajiloo et al. (2001) and Aliyu et al. (2016) observed a remarkable collapse of all the data under consideration producing a good fit. It was 
observed that this dimensionless group also collapsed the experimental data very well. Aliyu et al (2016) successfully presented a correlation to predict interfacial friction factor for different pipe diameters ranging from 15.6 to $101.6 \mathrm{~mm}$. The aim was to develop a correlation which worked independent of pipe diameter. To achieve this, they introduced a dimensionless group, $\left(\frac{t}{D} F r_{g}\right)$ consisting of the gas phase Froude number which characterizes the gravitational wave velocity of the gas-liquid interface and the film thickness non-dimensionalised pipe diameter.

To account for the effect of liquid viscosity in their model development, authors including Baba et al. (2017) and Al-Ruhaimani et al. (2017) have utilized similar approaches. In this study, liquid viscosity number, $N_{f}$ expressed by Equation (18) is used.

$N_{f}=\frac{D^{3 / 2}\left(g \rho_{l}\left(\rho_{l}-\rho_{g}\right)\right)^{0.5}}{\mu_{l}}$

Therefore, a new correlation which integrates the dimensionless groups discussed was developed for the experimental data, the general form of which was expressed as:

$f_{i} / f_{g}=A\left(t_{g}^{+} R e_{g}^{-0.2}\right)^{\alpha}\left(\frac{t}{D} F r_{g}\right)^{\beta} N_{f}^{\gamma}$

where A, $\alpha, \beta$ and $\gamma$ are constants to be determined by fitting the experimental data obtained to Eq. 19. To obtain the constants in Eq. (19), the method of non-linear least squares, a powerful technique, easily implemented in Microsoft Excel was employed.

To do this, Eq. (19) was re-written as follows:

$r_{i}=\left(f_{i} / f_{g}\right)_{\text {exp }, i}-\left(A\left(t_{g}^{+} \operatorname{Re}_{g}^{-0.2}\right)^{\alpha}\left(\frac{t}{D} F r_{g}\right)^{\beta} N_{f}^{\gamma}\right)_{\text {pred }, i}$ 
where $\mathrm{r}$ is the residual being the difference between each experimental point $(\exp , i)$ and the corresponding predicted point (pred,i). Though difficult to achieve as a result of random errors present in experimental measurements, an ideal value of $r_{i}=0$ is desired. There is no closed form solution for Eq. (20) and an infinite number of solutions can be obtained. Therefore, the best values for the constants are those that present the minimum value of the sum of squares of the residual $S$ across the entire experimental database. This is obtained by solving the non-linear least squares minimisation problem as follows:

$\min S=\sum_{i=1}^{N} r_{i}^{2}=\sum_{i=1}^{N}\left\{\left(f_{i} / f_{g}\right)_{e x p, i}-\left(A\left(t_{g}^{+} \operatorname{Re}_{g}^{-0.2}\right)^{\alpha}\left(\frac{t}{D} F r_{g}\right)^{\beta} N_{f}^{\gamma}\right)_{p r e d, i}\right\}^{2}$

where $\mathrm{N}$ is the number of datapoints in the databank. Eq. (21) is solved iteratively using the GaussNewton deterministic algorithm embedded in the Solver add-in available in Microsoft Excel. Initial values for the constants were provided. Efforts were made to ensure these values were as realistic as possible with a view to facilitate easy convergence of the algorithm and also to obtain a solution with realistic coefficients. The following expression (Eq. 22) was obtained after the algorithm was implemented.

$$
\begin{aligned}
& f_{i} / f_{g}=0.036539\left(t_{g}^{+} R e_{g}^{-0.2}\right)^{1.417}\left(\frac{t}{D} F r_{g}\right)^{-1.331} N_{f}^{0.037} \\
& f_{g}=0.046 R e_{g}^{-0.2}
\end{aligned}
$$

Equations (22) and (23) is a departure from the classic Wallis-type equation which presents a good performance for small values of $(\mathrm{t} / \mathrm{D})$. The combined dimensionless group consisting of superficial gas Froude number and dimensionless film thickness carries a negative index of -1.33 indicating a negative relationship with $f_{i} / f_{g}$. The index obtained for the liquid viscosity number is 0.037 . On the other hand, $\left(t_{g}^{+} R e_{g}\right)$ carries a positive index of 1.42 , The index obtained for $\left(\frac{t}{D} F r_{g}\right)$ is within 
the range of the obtained by previous authors in their correlations for $f_{i} / f_{g}$ (Hajiloo et al., 2001; Aliyu et al., 2016).

A pictorial comparison of predictions of the model indicates that it agrees well with the data at all viscosities considered (Figure 12). Statistical evaluation of the results was implemented using R, AAPE and APE (Eq. 24-26) which yielded values of 0.9898, 5.17, and 1.89 respectively. All the data points fell within an accuracy $\pm 20 \%$ (Figure 12). Further, Figure 13 shows the percentage errors calculated from Equation (22 and 23) plotted against superficial gas velocity. It can be seen that the overall majority of the percentage errors are within $10 \%$.

$R=\frac{\sum_{m=1}^{n}\left[\left(Y_{E x p, m}-\bar{Y}_{E x p, m}\right) \times\left(Y_{\text {pred }, m}-\bar{Y}_{\text {pred }, m}\right)\right]}{\sqrt{\sum_{m=1}^{n}\left(Y_{E x p, m}-\bar{Y}_{E x p, m}\right)^{2} \times \sum_{m=1}^{n}\left(Y_{\text {Pred }, m}-\bar{Y}_{\text {Pred }, m}\right)^{2}}}$

$\bar{Y}_{E x p, m}$ is the average of the experimental values.

$A A P E=\left[\frac{1}{n} \sum_{m=1}^{n}\left|\frac{Y_{\text {Exp }, m}-Y_{\text {Pred }, m}}{Y_{E x p, m}}\right|\right] \times 100$

$A P E=\left[\frac{1}{n} \sum_{m=1}^{n} \frac{Y_{E x p, m}-Y_{P r e d, m}}{Y_{E x p, m}}\right] \times 100$

\section{Extension of correlation to low viscosity data}

Numerous correlations which predict interfacial friction factor in annular flows exist. Air-water based correlations, however, dominate available methods for estimating this parameter. Air-water based and low viscosity correlations present unsatisfactory results when utilized for higher viscosity flows (McNeil and Stuart, 2003). Correlations developed from higher viscosity data also may predict low viscosity flow with unsatisfactory results. Despite the availability of a plethora of correlations, choices of suitable correlations sometimes present challenges for designers due to their limited applications especially in cases where liquid viscosity is of utmost importance. This 
challenge brings to the fore the need for development of a model that can accurately provide accurate predictions for interfacial friction factor in both low and higher viscosity flows. The study extended the application of the correlation data obtained using liquids of lower viscosities. This was achieved by augmenting the current experimental data with reported experimental data obtained by Skopich et al. (2015), Alamu (2010), Fore and Dukler (1995) and Al-Ruhaimani et al. (2017). Altogether, 111 data points (21 of which were obtained at higher liquid viscosity) were used for this correlation. Utilizing the same dimensionless parameters, the resulting non-linear least square regression obtained is expressed as follows (Eq. 27):

$f_{i} / f_{g}=0.010346\left(t_{g}^{+} R e_{g}^{-0.2}\right)^{1.809}\left(\frac{t}{D} F r_{g}\right)^{-1.191} N_{f}^{0.001}$

$f_{g}=0.046 R e_{g}^{-0.2}$

Here, the combined dimensionless group consisting of gas Froude number and dimensionless film thickness also carries a negative index but experiences an increase $(-1.191) . \quad\left(t_{g}^{+} R e_{g}^{-0.2}\right)$ also carries a comparatively higher positive index of 1.809 . The index of $N_{f}$, however, experiences a reduction (0.001). This could be attributed to the combining effect of the datasets employed for the development of the correlation and the dominance of the lower viscosity data. It is therefore conceivable that the effect of viscosity will be more apparent should more data become available at higher viscosities in future studies. Nevertheless, we note the model's ability to capture interfacial friction factor across wide viscosity ranges. The results of evaluation of predictions of the correlation are presented in Table 6 while comparison of predictions of the correlation with experimental data presented in Figure 14.

From the results, it can be observed that the predictions of the correlation agree with all experimental data. The correlation predicts the data of Skopich et al. (2015) very well with 
reasonable prediction error (AAPE=24.55) and overprediction (APE=-13.26). Skopich et al. (2015) employed the largest pipe diameter in the dataset. The results indicate that the correlation is capable of good predictions for datasets obtained with conduits with large diameters. The prediction errors for the Fore and Dukler (1995) air-water (AAPE=59.76) and air-water/glycerine (AAPE=50.79) data are comparatively high but can be considered satisfactory. It appears the data obtained using air-water/glycerine is predicted with comparatively lower error. It is possible the effect of viscosity is properly accounted for. Both datasets are, however, underpredicted by the correlation. The correlation performs well on the Al-Ruhaimani et al. (2017) dataset with the lowest prediction errors $(\mathrm{AAPE}=1.98)$ and overprediction $(\mathrm{APE}=-0.26)$. Overall, the performance of the correlation on the entire dataset is satisfactory (AAPE $=42.88$ ). The results indicate the experimental data is reasonably underpredicted $(\mathrm{APE}=37.69)$ while majority of the data points can be explained by the correlation $\left(\mathrm{R}^{2}=0.999\right)$. Further, majority of the predicted data points fall within the $\pm 60 \%$ accuracy band.

\section{Comparison with an Artificial Neural Network model}

Artificial neural networks (ANN) are bio-inspired methods (Ahmadi et al., 2016) that consist of numerous simple interconnected elements known as neurons which mimic the functions of biological neurons. The neurons are organized in layers and bound to weighted connections akin to synapses of the human brain (Azizi et al., 2016). The beneficial characteristics of this approach have adequately been reported by (Dayhoff, 1990; Nawi et al., 2013; Shokrollahi et al., 2013; Aliyu, 2015; Ahmadi et al., 2016) . Essentially, the ability of ANN (accredited to its unique mathematical structures) to provide an alternative approach for numerous engineering problems that are difficult to describe or solve using normal methods (Dayhoff, 1990; Ahmadi et al., 2016) is making it more attractive for adoption. Further, the mechanism of operation employed by this 
network is adequately described by Azizi et al.(2016a;2016b). A three-layer MLP network has been mathematically proven to be capable to approximate all categories of functions with no consideration to their complexities (Valeh-e-sheyda et al., 2010).

In order to obtain higher accuracy, several authors have utilized ANN to predict important multiphase flow parameters including flow pattern (Ternyik et al., 1995; Osman, 2004; Zhao et al., 2013; Al-Naser et al., 2016; Figueiredo et al., 2016; Hamidi et al., 2018; Hanus et al., 2018), liquid holdup (Ternyik et al., 1995; Shippen and Scott, 2004; Mohammadi, 2006; Azizi et al., 2016a; Zhao et al., 2019), heat transfer (Boostani et al., 2017; Hamidi et al., 2018), gas void fraction (Azizi et al., 2016a; Parrales et al., 2018), pressure gradient (Bar et al., 2010; Azizi and Karimi, 2015) under different flow conditions using varied gas-liquid mixtures and pipe dimensions and geometries. Other researchers have employed this method to determine gas and liquid properties (El-Sebakhy, 2009; Kamyab et al., 2010; Ahmadi et al., 2016; Roshani and Nazemi, 2017; Farzaneh-Gord et al., 2018).

It is worthy to note that despite the accuracy of the ANN model, it is empirical in nature. This means it may present less accurate results when applied to flow conditions outside the ranges for which it was developed. For this reason, ANN models generally require a large amount of data to make it fully relevant and accurate for a wide range of flow conditions. Furthermore, ANN models lack the information required to explain the physical phenomena observed during the flow regimes.

In this study, the neural network toolbox of MATLAB was employed to design networks to predict interfacial friction factor, $f_{i}$. A schematic representation of the 3-input-1-output three-layer ANN architecture for the proposed network with 16 neurons is shown in Figure 15. A feed-forward with the back-propagation network architecture was selected and utilized. One hidden layer was adopted to obtain accurate predictions. To identify the optimal model, both tansig and logsig 
transfer (or activation) functions were utilized in the hidden layer of the feedforward backpropagation (FFBP) networks. For both networks, a linear output function was utilized for the output layer neurons.

Both artificial neural networks were modelled using Equations (28) and (29):

$f_{i}=\left[\sum_{i=1}^{N} w_{2 i} \operatorname{tansig}\left(\sum_{J=1}^{J} w_{1 i, j} x_{j}+b_{1 i}\right)\right]+b_{2 i}$

$f_{i}=\left[\sum_{i=1}^{N} w_{2 i} \log \operatorname{sig}\left(\sum_{J=1}^{J} w_{1 i, j} x_{j}+b_{1 i}\right)\right]+b_{2 i}$

where $x_{j}=\left(x_{1}, x_{2}, x_{3}, \ldots, x_{J}\right)^{T}$ represents the input sample. In our case, the input sample consisted of values of $\left(t_{g}^{+} R e_{g}\right),\left(\frac{t}{D} F r_{g}\right)$ and $N_{f}$ as was used for the correlation. The interfacial friction factor, $f_{i}$ was the linear output of the hidden neurons and an output function used on the neurons. $\mathrm{J}$ and $\mathrm{N}$ are the number of the input variables and hidden nodes respectively. $w_{1 i, j}$ and $w_{2 i}$ represent the hidden layer and the output layer weight matrices respectively. $b_{1 i}$ and $b_{2 i}$ represent the corresponding bias vectors. The values of these coefficients are provided in Appendix Table (A.1).

Efforts were made to improve network performance by disregarding unnecessary input variables to placate the curse of dimensionality (Haykin, 1998; Shippen and Scott, 2004). The networks were designed and trained using a total of 148 experimental data points consisting of the current experimental data and those reported by Skopich et al. (2015), Alamu (2010), Fore and Dukler (1995) and Al-Ruhaimani et al. (2017). To avoid numerical overflows due to utilization of very small or very large weights, Input data was scaled to a range of [-1,1] (Aydiner et al., 2005).

The network was trained using the Levenberg - Marquardt (LM) algorithm which is recommended for training of the type of neural network selected (Hagan and Menhaj, 1994; Saini and Soni, 2002) 
and to evaluate the method of convergence. The LM algorithm was adopted due to its capacity to train rapidly and efficiently and in addition increase the convergence speed of the ANN with MLP architectures (Hagan and Menhaj, 1994). Further, it was selected because it is suited to training networks in which the performance index calculated is mean squared error (MSE) which was the case for this study.

The dividerand algorithm was implemented to ensure that data input parameters were randomly divided into three sets: training, validation and testing. The training data set is used for the development and adjustment of weights and biases of the network. The dataset for validation is used to ensure accuracy of and generalization of the network during the training phase while the testing set is used to evaluate the final performance of the trained network (Azizi and Karimi, 2015). For this study, 65\% (97 data points) was used for training, 15\% (21 data points) for validation and 20\% (30 data points) for testing.

The MATLAB toolbox ensures that number of neurons in the input and output layers is equal to the number of input and output parameters respectively by default. However, the number of neurons in the hidden layer differ based on the complexity of the problem. Choice of the optimal number of neurons is usually by a trial and error method (Yan et al., 2018). The optimal number of neurons for this study was estimated by minimizing the mean squared error (MSE) of the testing data set based on the expression in Equation (30).

$M S E=\frac{1}{n} \sum_{m=1}^{n}\left(Y_{E x p, m}-Y_{\text {Pred }, m}\right)^{2}$

where $\mathrm{n}$ is the number of data points, $Y_{\text {Exp,m }}$ is the experimental value and $Y_{\text {Pred,m }}$ is the predicted value obtained from the neural network model. 
It is noteworthy to point out that the optimal number of neurons in the hidden layer, as well as their related weights and biases are not known at the developmental stage of the network and hence must be optimized. To achieve this, the training process for each network was performed 200 times for each number of neurons in the hidden layer.

The number of neurons for each network was varied from 1-20 with several runs performed for each network with the aim of preventing wrong selection of initial weights. Performance of the testing data using the tansig and logsig transfer functions for different neuron configurations are presented in Figure 17. Eventually, the network with the best performance (lowest MSE value) for testing data was selected as the optimal ANN model. Performance of the optimal model was evaluated with coefficient of correlation (R) and average absolute percent error (AAPE), average percentage error (APE) (Equations 24-26) and the chi-square test defined in Equation (31).

$\chi^{2}=\sum_{i=1}^{n} \frac{\left(Y_{\text {observed }}-Y_{\text {predicted }}\right)^{2}}{\text { Ypredicted }}$

Finally, for interfacial friction factor, $f_{i}$, a network with a logsig transfer function, 16 neurons in the hidden layer (3-16-1), an MSE of 0.1964 and AAPE of 8.17 for the testing data was obtained as the optimum model with the best performance (Figure 15). Performance evaluation of selected ANN model for training, validation, testing and all data sets is presented in Table 7. A chi-square test performed for the overall data for both liquid holdup and pressure yielded a result of 1.0 respectively indicating that statistically, there is no difference between the experimental and predictions of the ANN models.

From Table 7, it can be observed that model predictions were made with low mean squared errors (MSE) and average absolute percent errors (AAPE) respectively. Low MSE values were achieved for training and testing data set. Generally, the MSE values calculated for all the datasets indicate 
that the model is well fitted while the prediction errors are low. As suggested by Mohammadi (2006), the results verify the success of the neural network to recognize the implicit relationship between input and output variables.

From Table 8, it can be observed that the experimental datasets utilized for the development of the ANN model represent a wide range of flow conditions, fluid properties, pipe diameters as well as gas and liquid viscosities. Despite the differences in the experimental data, the ANN model is found to predict each dataset for both low and high viscosities accurately with lower prediction errors (Table 8, Figure 17). Further, all related over- and underprediction is within reasonable limits. It is important to note the ability of the ANN model to accommodate and accurately predict additional data. For this model, the data of Alamu (2010) is added and predicted accurately; an exercise which proved futile during development of the correlation in Equation (27). Finally, the entire dataset set is predicted accurately with lower prediction error (AAPE=6.78) and reasonable overprediction $(\mathrm{APE}=-1.19)$.

\section{Conclusion}

In this work, we reported an experimental investigation of vertical air and oil (with viscosities $100-330 \mathrm{mPa}$ s) flow in a $0.060-\mathrm{m}$ ID pipe. Superficial air and oil velocity ranges are from 9.81 to $59.06 \mathrm{~m} / \mathrm{s}$ and 0.024 to $0.165 \mathrm{~m} / \mathrm{s}$ respectively. Flow regimes were observed by visual observation as well as by studying video recordings of the flows. Transition to annular and annular flow patterns were observed to be shifted to higher gas velocities than occurs in air-water flows, and this was found to correspond to a change in pressure gradient slope. Additionally, increases in liquid viscosity leads to corresponding increases in liquid holdup, pressure drop, liquid film thickness and interfacial friction factor respectively. 
Quick closing valves were used to measure the liquid holdup, which was in turn used to estimate the film thickness, since in vertical annular flow, the film is circumferentially uniform and a simple geometrical relationship applies. This along with the pressure gradient was used to calculate the interfacial friction factor by applying a momentum balance around the droplet-laden gas core. The calculated experimental interfacial friction factors were used to compare with 16 correlations from the open literature. Correlations of Fore et al. (2000), Holt et al. (1999) and Blasius (Aliyu et al., 2017) are found to predict the experimental data satisfactorily. For our experimental data, obtained from higher viscosity flows, a new correlation was derived which is a function of including liquid viscosity number, $N_{f}$ and combined dimensionless parameters $\left(t_{g}^{+} R e_{g}^{-0.2}\right)$ and $\left(\frac{t}{D} F r_{g}\right)$ is developed. The results indicate that predictions of the correlation agree very well with the combined low/higher viscosity data and performs better than the existing correlations we considered.

The correlation is extended to low viscous data by combining the experimental and reported datasets of Skopich et al. (2015), Al-Ruhaimani et al. (2017), Fore et al (1995) (air-water and airwater/glycerine mixtures). Evaluation of the results indicate that predictions of the correlation also agree with the experimental data. Utilization of more data would greatly enhance the efficacy of the correlation. Using the same correlating parameters and other reported data, an Artificial Neural Network (ANN) model capable of predicting the interfacial friction factor in flows involving both low and higher viscosity liquids, is developed. Even though it cannot be used for numerical simulations, compared to the correlation, the ANN presented a superior performance in describing the combined experimental database. 


\section{Nomenclature}

\section{Roman symbols}

A Area, $\left[\mathrm{m}^{2}\right]$

$D$ Diameter, [m]

$-\frac{d P}{d z} \quad$ pressure gradient, $\mathrm{Pa} / \mathrm{m}$

$e \quad$ entrainment droplet fraction, [ - ]

$f_{i} \quad$ interfacial friction factor [ - ]

$f_{g} \quad$ single-phase friction factor, [ - ]

$\dot{m} \quad$ mass flow rate, $\mathrm{kg} \mathrm{m}^{-2} \mathrm{~s}^{-1}$

$N_{f} \quad$ liquid viscosity number, [ - ]

$\mathrm{Fr}_{g} \quad$ superficial gas Froude number, [ - ]

$\mathrm{Fr}_{l} \quad$ superficial liquid Froude number, [ - ]

$R e_{g} \quad$ superficial gas Reynolds number, [ - ]

$R e_{l} \quad$ superficial liquid Reynolds number, [ - ]

$R e_{l f} \quad$ liquid film Reynolds number, [ - ]

$t \quad$ liquid film thickness, $(\mathrm{m})$

$(t / D)$ dimensionless liquid film thickness, [ - ]

$t^{+}, t_{g}^{+}$liquid film thickness non-dimensionalised by the friction velocity, [ - ]

$\Delta \mathrm{L} \quad$ change in pipe length, (m)

$(L / D)$ length to diameter ratio, $[-]$

$\Delta \mathrm{P} \quad$ differential pressure, $(\mathrm{Pa})$

$v \quad$ velocity, $(\mathrm{m} / \mathrm{s})$

We Weber number, [- ]

$x \quad$ gas quality, [- ]

$X \quad$ Martinelli parameter, [- ]

\section{Greek symbols}

$\tau_{i} \quad$ interfacial shear stress, $(\mathrm{Pa})$

$\rho \quad$ density, $\left(\mathrm{kg} / \mathrm{m}^{3}\right)$

$\mu \quad$ dynamic viscosity, $(\mathrm{kg} / \mathrm{s}-\mathrm{m})$

$v \quad$ dynamic viscosity, $\left(\mathrm{m}^{2} / \mathrm{s}\right)$

$\sigma \quad$ surface tension, $(\mathrm{N} / \mathrm{m})$

$\varepsilon \quad$ cross-sectionally averaged gas void fraction, [ - ]

$\gamma \quad$ droplet holdup, [ - ]

\section{Subscripts}

c core region

$d$ droplet 
$l \quad$ liquid

$g, G \quad$ gas

sl superficial liquid

$s g \quad$ superficial gas

$w \quad$ water

\section{Acknowledgement}

This work was supported by National Science and Technology Major Project of the Ministry of Science and Technology of China under Grant number 2017ZX05030-003-005.

\section{Conflict of interest}

On behalf of all author, I declare that there is no conflict of interest.

\section{References}

Ahmadi, M. A. et al. (2016) 'An accurate model to predict drilling fluid density at wellbore conditions', Egyptian Journal of Petroleum. Egyptian Petroleum Research Institute, pp. 110. doi: 10.1016/j.ejpe.2016.12.002.

Al-Naser, M., Elshafei, M. and Al-Sarkhi, A. (2016) 'Artificial neural network application for multiphase flow patterns detection: A new approach', Journal of Petroleum Science and Engineering, 145, pp. 548-564. doi: 10.1016/j.petrol.2016.06.029.

Al-Ruhaimani, F. et al. (2017) 'Experimental Analysis and Model Evaluation of High-LiquidViscosity Two-Phase Upward Vertical Pipe Flow', SPE Journal, 22(03), pp. 0712-0735. doi: 10.2118/184401-PA.

Alamu, M. B. (2010) Investigation of periodic structures in gas-liquid flow. (Ph.D thesis). University of Nottingham.

Aliyu, A. M. (2015) Vertical annular gas-liquid two-phase flow in large diameter pipes. Cranfield University.

Aliyu, Aliyu M. et al. (2016) 'Interfacial shear in adiabatic downward gas/liquid co-current annular flow in pipes', Experimental Thermal and Fluid Science, 72, pp. 75-87. doi: 10.1016/j.expthermflusci.2015.10.025.

Aliyu, A.M. et al. (2016) 'Interfacial shear in adiabatic downward gas/liquid co-current annular flow in pipes', Experimental Thermal and Fluid Science, 72. doi: 10.1016/j.expthermflusci.2015.10.025.

Aliyu, Aliyu Musa et al. (2017) 'Interfacial friction in upward annular gas-liquid two-phase flow in pipes', Experimental Thermal and Fluid Science, 84, pp. 90-109. doi: 
10.1016/j.expthermflusci.2017.02.006.

Aliyu, Aliyu M. et al. (2017) 'Prediction of entrained droplet fraction in co-current annular gasliquid flow in vertical pipes', Experimental Thermal and Fluid Science. Elsevier Inc., 85, pp. 287-304. doi: 10.1016/j.expthermflusci.2017.03.012.

Alves, I. M. et al. (1991) 'Modeling Annular Flow Behavior for Gas Wells', SPE Production Engineering, 6(04), pp. 435-440. doi: 10.2118/20384-PA.

Ambrosini, W., Andreussi, P. and Azzopardi, B. J. (1991) 'A physically based correlation for drop size in annular flow', International Journal of Multiphase Flow, 17(4), pp. 497-507. doi: 10.1016/0301-9322(91)90045-5.

Asali, J. C., Hanratty, T. J. and Andreussi, P. (1985) 'Interfacial Drag and Film Height for Vertical Annular Flow', American Institute of Chemical Engineers, 31(6), pp. 895-902. doi: 10.1002/aic.690310604.

Aydiner, C., Demir, I. and Yildiz, E. (2005) 'Modeling of flux decline in crossflow microfiltration using neural networks: The case of phosphate removal', Journal of Membrane Science, 248(1-2), pp. 53-62. doi: 10.1016/j.memsci.2004.07.036.

Aziz, K., Govier, G. W. and Fogarasi, M. (1972) 'Pressure Drop in Wells Producing Oil and Gas.', Journal of Canadian Petroleum Technology, 11(3), pp. 38-48. doi: 10.2118/72-0304 .

Azizi, S., Ahmadloo, E. and Awad, M. M. (2016) 'Prediction of void fraction for gas-liquid flow in horizontal, upward and downward inclined pipes using artificial neural network', International Journal of Multiphase Flow. Elsevier Ltd, 87(August), pp. 35-44. doi: 10.1016/j.ijmultiphaseflow.2016.08.004.

Azizi, S., Awad, M. M. and Ahmadloo, E. (2016) 'International Journal of Multiphase Flow Prediction of water holdup in vertical and inclined oil - water two-phase flow using artificial neural network', International Journal of Multiphase Flow. Elsevier Ltd, 80, pp. 181-187. doi: 10.1016/j.ijmultiphaseflow.2015.12.010.

Azizi, S. and Karimi, H. (2015) 'An Artificial Neural Network Model for Predicting the Pressure Gradient in Horizontal Oil - Water Separated Flow', 49(2), pp. 131-141.

Baba, Y. D. et al. (2017) 'Slug frequency in high viscosity oil-gas two-phase fl ow : Experiment and prediction', Flow Measurement and Instrumentation. Elsevier, 54(December 2016), pp. 109-123. doi: 10.1016/j.flowmeasinst.2017.01.002.

Bar, N. et al. (2010) 'Prediction of pressure drop using artificial neural network for nonNewtonian liquid flow through piping components', Journal of Petroleum Science and Engineering. Elsevier B.V., 71(3-4), pp. 187-194. doi: 10.1016/j.petrol.2010.02.001.

Beggs, D. H. and Brill, J. P. (1973) ‘A Study of Two-Phase Flow in Inclined Pipes', Journal of Petroleum Technology, pp. 607-617. doi: 10.2118/4007-PA.

Belt, R. J., Van't Westende, J. M. C. and Portela, L. M. (2009) 'Prediction of the interfacial shear-stress in vertical annular flow', International Journal of Multiphase Flow, 35(7), pp. 689-697. doi: 10.1016/j.ijmultiphaseflow.2008.12.003. 
Bhagwat, S. M. and Ghajar, A. J. (2012) 'Similarities and differences in the flow patterns and void fraction in vertical upward and downward two phase flow', Experimental Thermal and Fluid Science. Elsevier Inc., 39, pp. 213-227. doi:

10.1016/j.expthermflusci.2012.01.026.

Boostani, M., Karimi, H. and Azizi, S. (2017) 'Heat transfer to oil-water flow in horizontal and inclined pipes: Experimental investigation and ANN modeling', International Journal of Thermal Sciences. Elsevier Masson SAS, 111, pp. 340-350. doi:

10.1016/j.ijthermalsci.2016.09.005.

Cioncolini, A. and Thome, J. R. (2012) 'Void fraction prediction in annular two-phase flow', International Journal of Multiphase Flow. Elsevier Ltd, 43, pp. 72-84. doi: 10.1016/j.ijmultiphaseflow.2012.03.003.

Dayhoff, J. (1990) Neural-Network Architectures: An Introduction. New York: Van Nostrand Reinhold.

Duns, H. and Ros, N. C. J. (1963) 'Vertical flow of gas and liquid mixtures in wells', 6th World Petroleum Congress, pp. 451-465.

El-Sebakhy, E. A. (2009) 'Forecasting PVT properties of crude oil systems based on support vector machines modeling scheme', Journal of Petroleum Science and Engineering. Elsevier B.V., 64(1-4), pp. 25-34. doi: 10.1016/j.petrol.2008.12.006.

Farzaneh-Gord, M. et al. (2018) 'Precise calculation of natural gas sound speed using neural networks: An application in flow meter calibration', Flow Measurement and Instrumentation. Elsevier Ltd, 64, pp. 90-103. doi: 10.1016/j.flowmeasinst.2018.10.013.

Figueiredo, M. M. F. et al. (2016) 'The use of an ultrasonic technique and neural networks for identification of the flow pattern and measurement of the gas volume fraction in multiphase flows', Experimental Thermal and Fluid Science. Elsevier Inc., 70, pp. 29-50. doi: 10.1016/j.expthermflusci.2015.08.010.

Fore, L. ., Beus, S. . and Bauer, R. . (2000) 'Interfacial friction in gas-liquid annular flow: analogies to full and transition roughness', International Journal of Multiphase Flow, 26(11), pp. 1755-1769. doi: 10.1016/S0301-9322(99)00114-7.

Fore, L. B. and Dukler, A. E. (1995a) 'Droplet deposition and momentum transfer in annular flow’, AIChE Journal, 41(9), pp. 2040-2046. doi: 10.1002/aic.690410904.

Fore, L. B. and Dukler, A. E. (1995b) 'The distribution of drop size and velocity in gas-liquid annular flow', International Journal of Multiphase Flow, 21(2), pp. 137-149. doi: 10.1016/0301-9322(94)00061-N.

Fukano, T. et al. (1985) 'Liquid films flowing concurrently with air in horizontal duct. 5th report Shear stress at gas-liguid interface.', Transactions of the Japan Society of Mechanical Engineers Series B, 51(462), pp. 494-502. doi: 10.1299/kikaib.51.494.

Fukano, T. and Furukawa, T. (1998) 'Prediction of the Effect of Liquid Viscosity on Interfacial Shear Stress and Frictional Pressure Drop in Vertical Upward Gas Liquid Annular Flow', International Journal of Multiphase Flow, 24(4), pp. 587-603. 
Guner, M. (2012) Liquid Loading of Gas Wells with Deviations from $0^{\circ}$ to $45^{\circ}$ (M.Sc thesis). McDougall School of Petroleum Engineering, University of Tulsa, USA.

Hagan, M. T. and Menhaj, M. B. (1994) 'Training Feedforward Networks with the Marquardt Algorithm', IEEE Transactions on Neural Networks, 5(6), pp. 989-993. doi: 10.1109/72.329697.

Hagedorn, A. and Brown, K. (1964) 'The Effect of Liquid Viscosity in Two-Phase Vertical Flow', Journal of Petroleum Technology, 16(2), pp. 203-210. doi: 10.2118/733-PA.

Hajiloo, M., Chang, B. H. and Mills, A. F. (2001) 'Interfacial shear in downward two-phase annular co-current flow', International Journal of Multiphase Flow, 27(6), pp. 1095-1108. doi: 10.1016/S0301-9322(00)00065-3.

Hamidi, M. J., Karimi, H. and Boostani, M. (2018) 'Flow patterns and heat transfer of oil-water two-phase upward flow in vertical pipe', International Journal of Thermal Sciences. Elsevier, 127(March), pp. 173-180. doi: 10.1016/j.ijthermalsci.2018.01.020.

Hanus, R. et al. (2018) 'Identification of liquid-gas flow regime in a pipeline using gamma-ray absorption technique and computational intelligence methods', Flow Measurement and Instrumentation. Elsevier Ltd, 60(September 2017), pp. 17-23. doi: 10.1016/j.flowmeasinst.2018.02.008.

Haykin, S. (1998) 'Neural Networks', Convergence, pp. 1-16. doi: 10.1109/79.487040.

Henstock, W. H. and Hanratty, T. J. (1976) 'The interfacial drag and the height of the wall layer in annular flows', AIChE Journal, 22(6), pp. 990-1000. doi: 10.1002/aic.690220607.

Holt, A. J., Azzopardi, B. J. and Biddulph, M. W. (1999) 'Calculation of Two-Phase Pressure Drop for Vertical Upflow in Narrow Passages by Means of a Flow Pattern Specific Model', Chemical Engineering Research and Design, 77(1), pp. 7-15. doi: $10.1205 / 026387699525828$.

Hori, K. et al. (1978) 'Study of ripple region in annular two-phase flow (Third report, effect of liquid viscosity on gas-liquid interfacial character and friction factor)', Trans. Jap. Soc. Mech. Eng., 44(387), pp. 3847-3856.

Jones, O. C. and Zuber, N. (1975) 'The interrelation between void fraction fluctuations and flow patterns in two-phase flow', International Journal of Multiphase Flow, 2(3), pp. 273-306. doi: 10.1016/0301-9322(75)90015-4.

Kaji, R. and Azzopardi, B. J. (2010) 'The effect of pipe diameter on the structure of gas / liquid flow in vertical pipes', International Journal of Multiphase Flow. Elsevier Ltd, 36(4), pp. 303-313. doi: 10.1016/j.ijmultiphaseflow.2009.11.010.

Kamyab, M. et al. (2010) 'Using artificial neural networks to estimate the z-factor for natural hydrocarbon gases', Journal of Petroleum Science and Engineering. Elsevier B.V., 73(34), pp. 248-257. doi: 10.1016/j.petrol.2010.07.006.

Kumar, R. and Edwards, D. P. (1996) 'Interfacial shear modelling in two-phase annular flow', in Proceedings of the 1996 ASME International Mechanical Engineering Congress and Exposition, November 17, 1996-November 22, 1996, ASME, Atlanta, GA, USA, pp. 381- 
389.

Lopes, J. C. B. and Dukler, A. E. (1986) 'Droplet entrainment in vertical annular flow and its contribution to momentum transfer', AIChE Journal, 32(9), pp. 1500-1515. doi: 10.1002/aic.690320911.

Maron, D. M. and Brauner, N. (1987) 'The role of interfacial mobility in determining the interfacial shear factor in two-phase wavy film flow', International Communications in Heat and Mass Transfer, 14(1), pp. 45-55. doi: 10.1016/0735-1933(87)90007-8.

Matsuyama, F. et al. (2017) 'Effects of surface tension on liquid film behavior and interfacial shear stress in upward annular flows in a vertical pipe', 7(5), pp. 164-171. doi: 10.5923/j.jmea.20170705.08.

McNeil, D. A. and Stuart, A. D. (2003) 'The effects of a highly viscous liquid phase on vertically upward two-phase flow in a pipe', International Journal of Multiphase Flow, 29(9), pp. 1523-1549. doi: 10.1016/S0301-9322(03)00122-8.

Van der Meulen, G. P. (2012) Churn-annular gas-liquid flows in large diameter vertical pipes (Ph.D thesis). University of Nottingham.

Moeck, E. O. (1970) 'Annular-dispersed two-phase flow and critical heat flux', p. 206. Available at: http://www.iaea.org/inis/collection/NCLCollectionStore/_Public/01/002/1002083.pdf.

Mohammadi, M. (2006) 'A Comprehensive Neural Network Model for Predicting Two-Phase Liquid Holdup Under Various Angles of Pipe Inclinations', in Canadian International Petroleum Conference. Petroleum Society of Canada, pp. 1-9. doi: 10.2118/2006-048.

Mukherjee, H. and Brill, J. P. (1985) 'Pressure Drop Correlations for Inclined Two-Phase Flow', Journal of Energy Resources Technology, 107(4), p. 549. doi: 10.1115/1.3231233.

Nawi, N. M., Khan, A. and Rehman, M. Z. (2013) 'A New Levenberg Marquardt based Back Propagation Algorithm Trained with Cuckoo Search', Procedia Technology. Elsevier B.V., 11(Iceei), pp. 18-23. doi: 10.1016/j.protcy.2013.12.157.

Orkiszewski, J. (1967) 'Predicting Two-Phase Pressure Drops in Vertical Pipe', Journal of Petroleum Technology, 19(6), pp. 829-838. doi: 10.2118/1546-PA.

Osman, E. A. (2004) 'Artificial Neural Network Models for Identifying Flow Regimes and Predicting Liquid Holdup in Horizontal Multiphase Flow', SPE Production \& Facilities. Society of Petroleum Engineers, 19(01), pp. 33-40. doi: 10.2118/86910-PA.

Pan, L. M. et al. (2015) 'The influences of gas-liquid interfacial properties on interfacial shear stress for vertical annular flow', International Journal of Heat and Mass Transfer. Elsevier Ltd, 89(2015), pp. 1172-1183. doi: 10.1016/j.ijheatmasstransfer.2015.06.022.

Parrales, A. et al. (2018) 'New void fraction equations for two-phase flow in helical heat exchangers using artificial neural networks', Applied Thermal Engineering. Elsevier Ltd, 130, pp. 149-160. doi: 10.1016/j.applthermaleng.2017.10.139.

Pinto del Corral, N. (2014) Analysis of Two-Phase Flow Pattern Maps.

Roshani, G. H. and Nazemi, E. (2017) 'Intelligent densitometry of petroleum products in 
stratified regime of two phase flows using gamma ray and neural network', Flow Measurement and Instrumentation. Elsevier Ltd, 58(September), pp. 6-11. doi: 10.1016/j.flowmeasinst.2017.09.007.

Saini, L. M. and Soni, M. K. (2002) 'Artificial neural network based peak load forecasting using Levenberg-Marquardt and quasi-Newton methods', IEE Proceedings - Generation, Transmission and Distribution, 149(5), p. 578. doi: 10.1049/ip-gtd:20020462.

Schmidt, J., Giesbrecht, H. and van der Geld, C. W. M. (2008) 'Phase and velocity distributions in vertically upward high-viscosity two-phase flow', International Journal of Multiphase Flow, 34(4), pp. 363-374. doi: 10.1016/j.ijmultiphaseflow.2007.10.013.

Shearer, C. J. and Nedderman, R. M. (1965) 'Pressure gradient and liquid film thickness in cocurrent upwards flow of gas/liquid mixtures: Application to film-cooler design', Chemical Engineering Science, 20(7), pp. 671-683. doi: 10.1016/0009-2509(65)80004-5.

Shippen, M. E. and Scott, S. L. (2004) 'A neural network model for prediction of liquid holdup in two-phase horizontal flow', Spe Production \& Facilities, 19(2), pp. 67-76.

Shokrollahi, A. et al. (2013) 'Intelligent model for prediction of CO2- Reservoir oil minimum miscibility pressure', Fuel. Elsevier Ltd, 112(May), pp. 375-384. doi: 10.1016/j.fuel.2013.04.036.

Skopich, A. et al. (2015) 'Pipe-Diameter Effect on Liquid Loading in Vertical Gas Wells', SPE Production \& Operations, 30(02), pp. 164-176. doi: 10.2118/164477-PA.

Taitel, Y., Bornea, D. and Dukler, A. (1980) 'Modelling Flow Pattern Transitions for Steady Upward Gas-Liquid Flow in Vertical Tubes', AIChE Journal, 26(3), pp. 345-354. doi: 10.1002/aic.690260304.

Ternyik, J., Bilgesu, H. I. and Mohaghegh, S. (1995) 'Virtual Measurement in Pipes: Part 2Liquid Holdup and Flow Pattern Correlations', in SPE Eastern Regional Meeting. First. Richardson, Texas: Society of Petroleum Engineers, pp. 35-44. doi: 10.2118/30976-MS.

Valeh-e-sheyda, P. et al. (2010) 'Application of Artificial Neural Networks for Estimation of the Reaction Rate in', pp. 4620-4626.

Vieira, R. E. et al. (2015) 'Experimental characterization of vertical gas-liquid pipe flow for annular and liquid loading conditions using dual Wire-Mesh Sensor', Experimental Thermal and Fluid Science. Elsevier Inc., 64, pp. 81-93. doi: 10.1016/j.expthermflusci.2015.02.007.

Wallis, G. B. (1969) One-Dimensional Two-phase Flow. McGraw Hill, New York.

Wang, Z. L., Gabriel, K. S. and Zhu, Z. F. (2004) 'The effects of gravity on the features of the interfacial waves in annular two-phase flow', Microgravity Science and Technology, 15(3), pp. 19-27. doi: 10.1007/BF02870961.

Willets, I. P. (1987) Non-aqueous annular two-phase flow (D.Phil. thesis). University of Oxford, U.K.

Wongwises, S. and Kongkiatwanitch, W. (2001) 'Interfacial friction factor in vertical upward 
gas-liquid annular two-phase flow', International Communications in Heat and Mass Transfer, 28(3), pp. 323-336. doi: 10.1016/S0735-1933(01)00238-X.

Wu, B. et al. (2017) 'A critical review of flow maps for gas-liquid flows in vertical pipes and annuli', Chemical Engineering Journal. Elsevier B.V., 326, pp. 350-377. doi: 10.1016/j.cej.2017.05.135.

Xue, Y. et al. (2016) 'Investigation on the void fraction of gas-liquid two-phase flows in vertically-downward pipes', International Communications in Heat and Mass Transfer. Elsevier Ltd, 77, pp. 1-8. doi: 10.1016/j.icheatmasstransfer.2016.06.009.

Yan, Y. et al. (2018) 'Application of soft computing techniques to multiphase flow measurement: A review', Flow Measurement and Instrumentation. Elsevier Ltd, 60(November 2017), pp. 30-43. doi: 10.1016/j.flowmeasinst.2018.02.017.

Yuan, M. (2011) Liquid Loading of Gas Wells (M.Sc thesis). McDougall School of Petroleum Engineering, University of Tulsa, USA.

Zangana, M. H. S. (2011) Film behaviour of vertical gas-Liquid Flow in a large diameter pipe. University of Nottingham. Available at: http://eprints.nottingham.ac.uk/12782/1/546275.pdf.

Zhang, H. Q. and Sarica, C. (2011) 'Low liquid loading gas/liquid pipe flow', Journal of Natural Gas Science and Engineering. Elsevier B.V, 3(2), pp. 413-422. doi: 10.1016/j.jngse.2011.03.001.

Zhang, H., Sarica, C. and Pereyra, E. (2012) 'Review of High-Viscosity Oil Multiphase Pipe Flow'.

Zhao, C., Wu, G. and Li, Y. (2019) 'Measurement of water content of oil-water two-phase flows using dual-frequency microwave method in combination with deep neural network', Measurement: Journal of the International Measurement Confederation, 131, pp. 92-99. doi: 10.1016/j.measurement.2018.08.028.

Zhao, Y., Bi, Q. and Hu, R. (2013) 'Recognition and measurement in the flow pattern and void fraction of gas-liquid two-phase flow in vertical upward pipes using the gamma densitometer', Applied Thermal Engineering. Elsevier Ltd, 60(1-2), pp. 398-410. doi: 10.1016/j.applthermaleng.2013.07.006. 


\section{Figures}

(a)

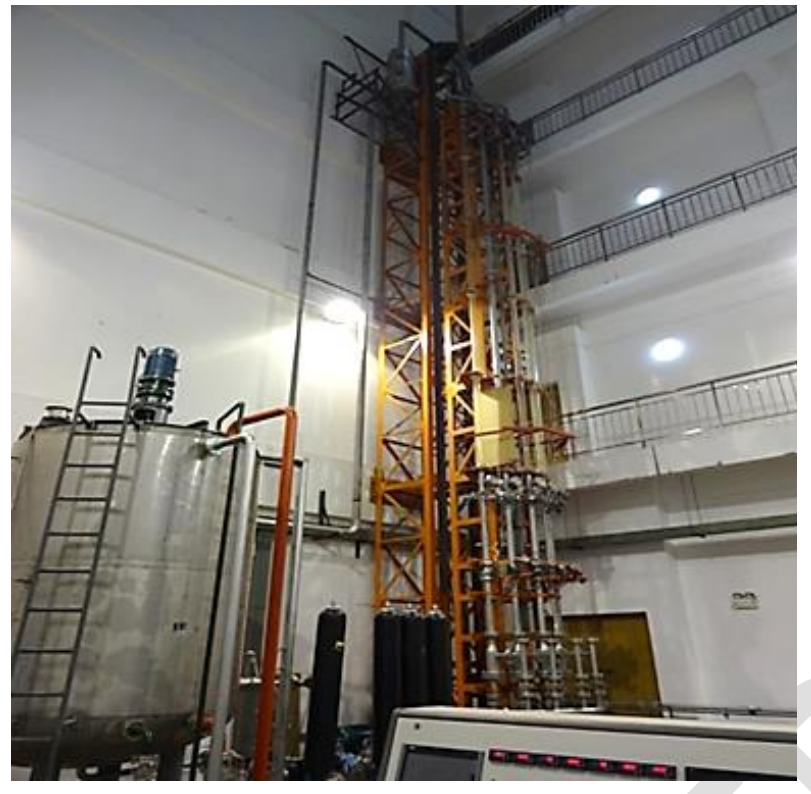

(b)

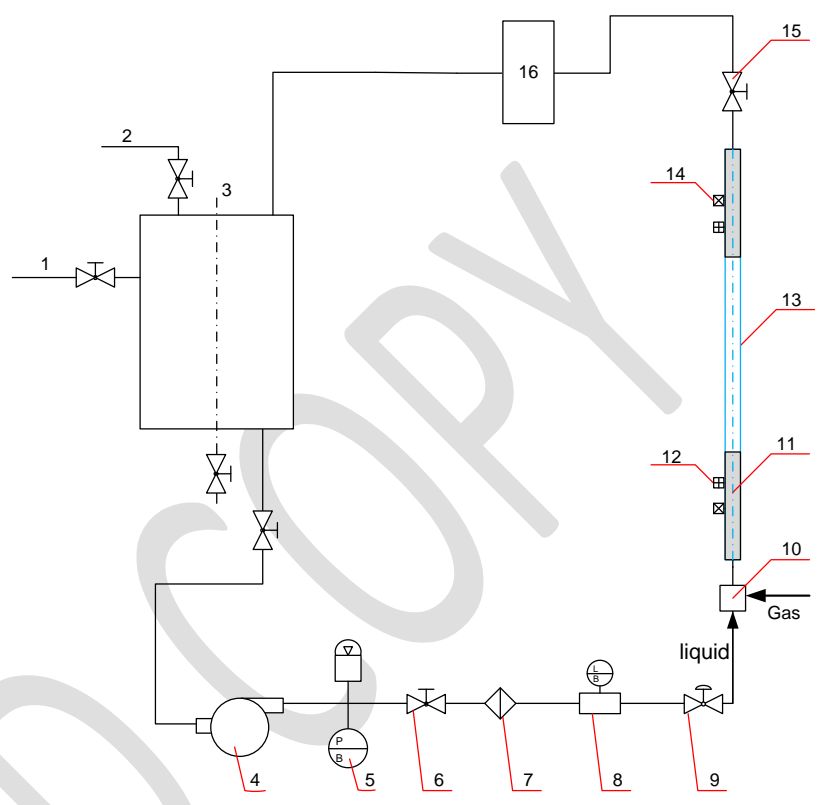

(c)

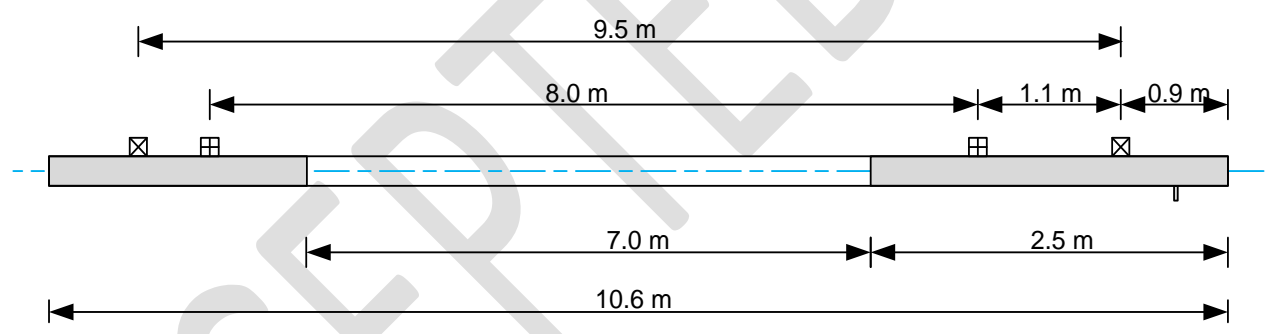

Figure 1: Experimental setup - (a): photo of the experimental rig in vertical position; (b): schematic diagram with numbers denoting (1) Flow Entrance of Oil (2) Flow Entrance of Water (3) Oil-Water Mixer (4) Liquid Pump (5) Pressure Meter (6) Regulator (7) Moisture Content Tester (8) Flow Meter (9) Adjusting Pressure Valve (10) Gas-Liquid Mixer (11) Stainless steel pipe (12) Pressure transducer (13) Acrylic viewing section

(14) Quick closing valve (QCV) (15) Valve (16) Gas-Liquid Separator; (c) Dimensions of test section 


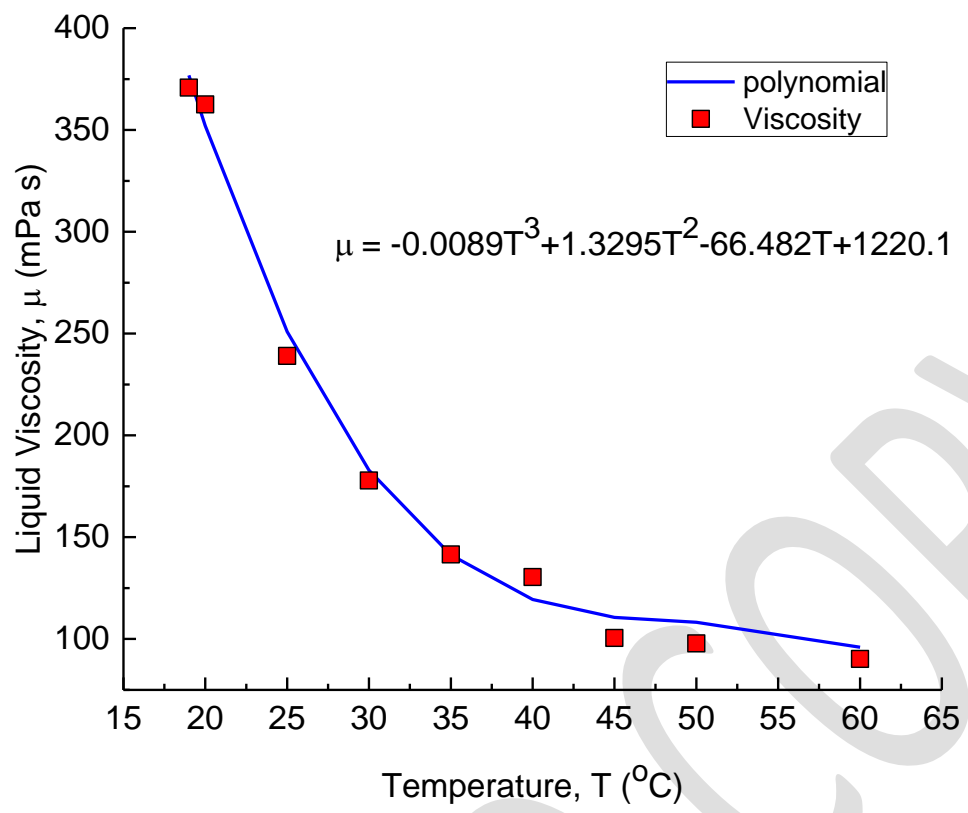

(a)

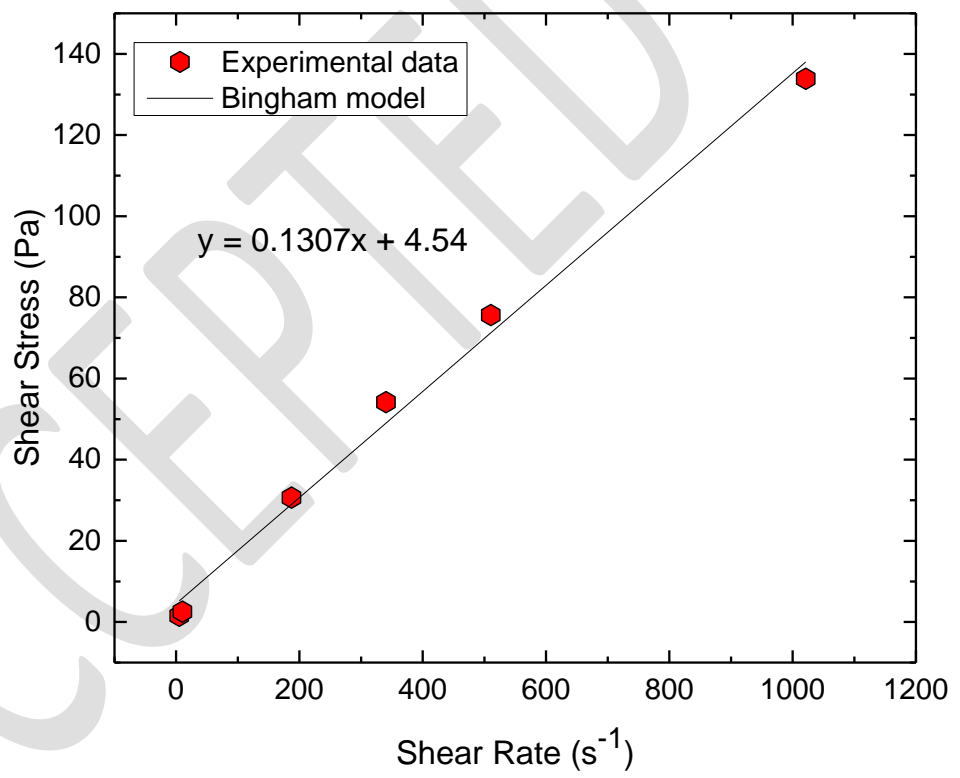

(b)

Figure 2: Properties of the oil: (a)variation of oil viscosity with temperature (b) variation of shear stress with shear strain 


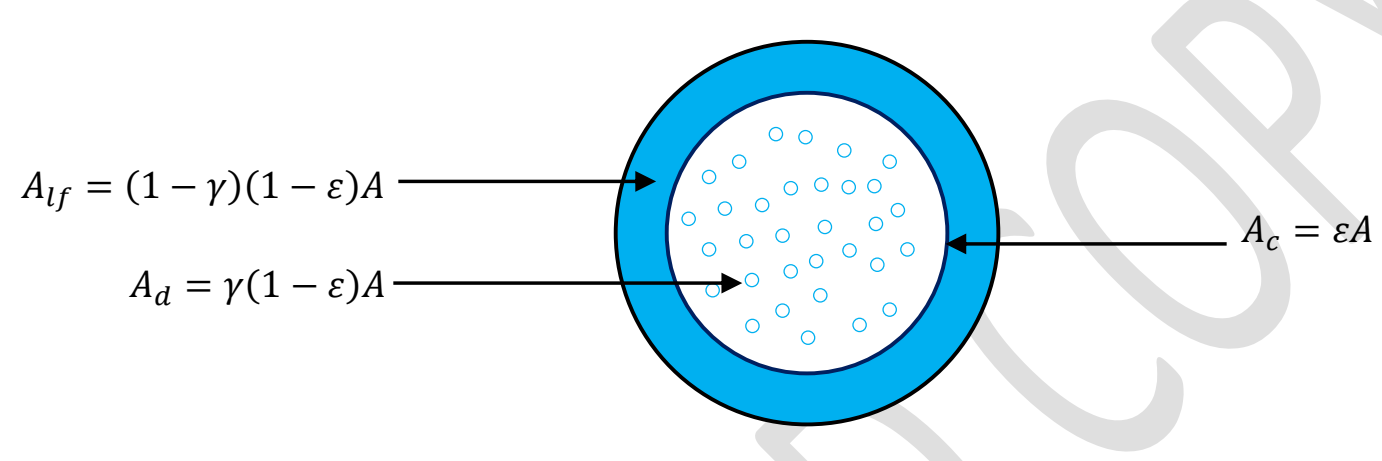

Figure 3: Representation of the notation of the various phases occupying the total pipe area (Aliyu et al., 2017) 


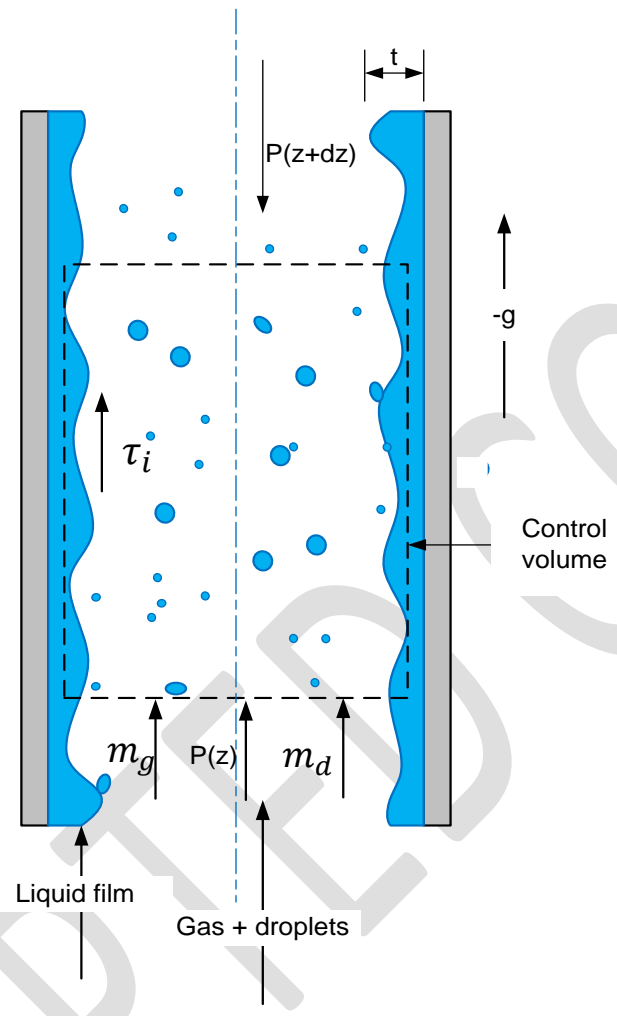

Figure 4: Control volume for the momentum balance in Eq. (14) (Wongwises and Kongkiatwanitch, 2001; Aliyu et al., 2017) 


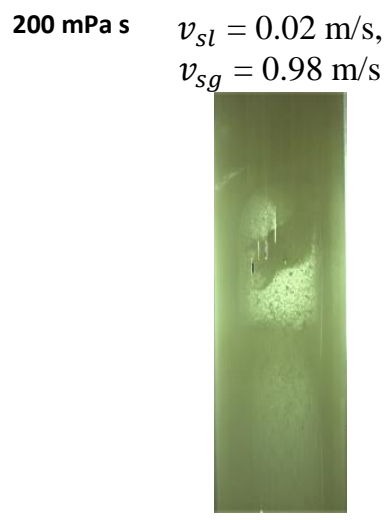

(a)

$$
\begin{array}{clcc}
v_{s l}=0.05 m / s & v_{s l}=0.05 m / s & v_{s l}=0.07 m / s & v_{s l}=0.07 m / s \\
v_{s g}=34.38 m / s & v_{s g}=39.29 m / s & v_{s g}=44.20 m / s & v_{s g}=58.93 m / s
\end{array}
$$

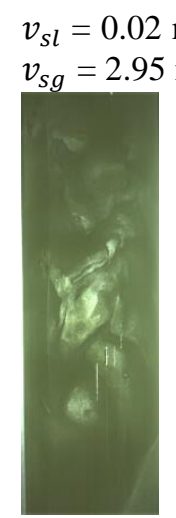

(b)

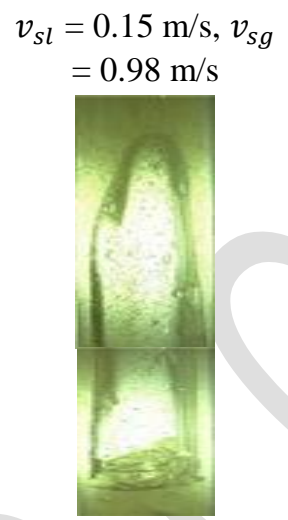

(c)

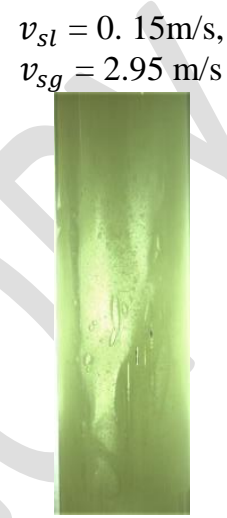

(d)

$200 \mathrm{mPa} s$

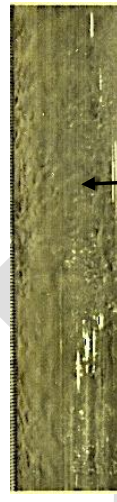

(e)

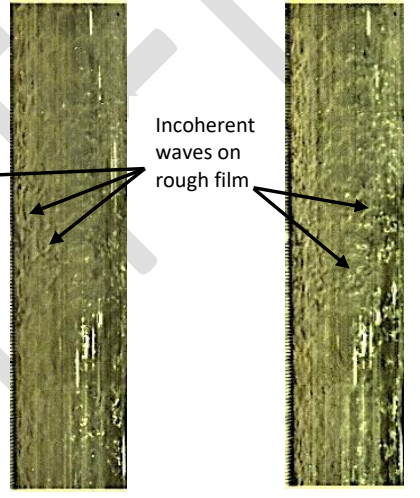

(f) (g)

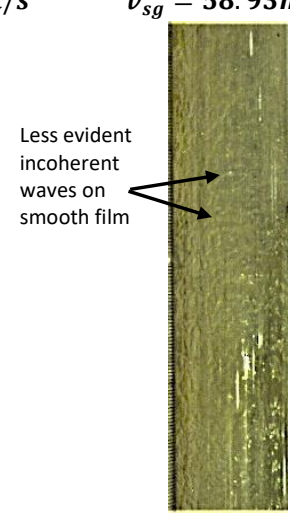

(h)

Figure 5: Behaviour of liquid film at liquid viscosity of $200 \mathrm{mPa} s$ at various slug and annular flow conditions 


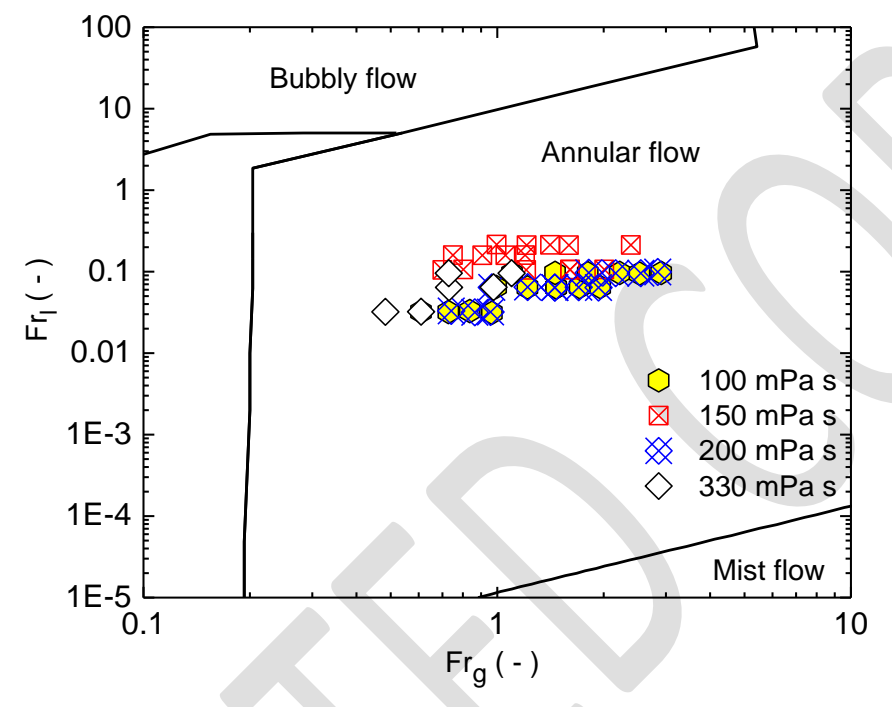

(a)

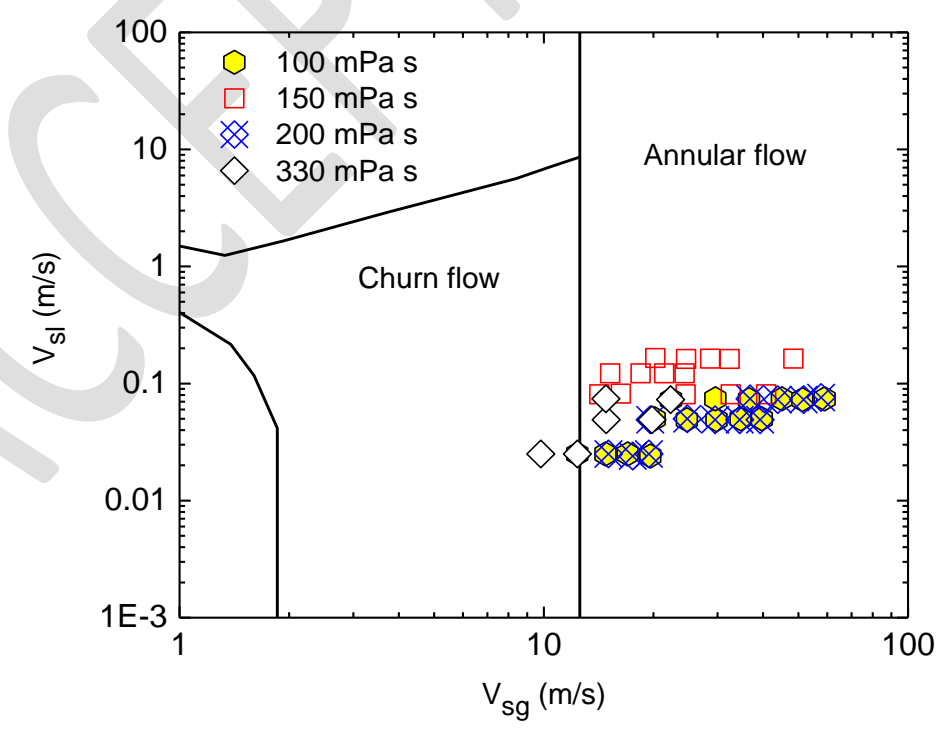

(b)

Figure 6: Experimental data super-imposed on the flow pattern maps of: (a) Shell Company (2007) and (b) Taitel et al. (1980) 
Published in Chemical Engineering Communications as Ribeiro et al.. https://doi.org/10.1080/00986445.2019.1647180 online on 29 August, 2019

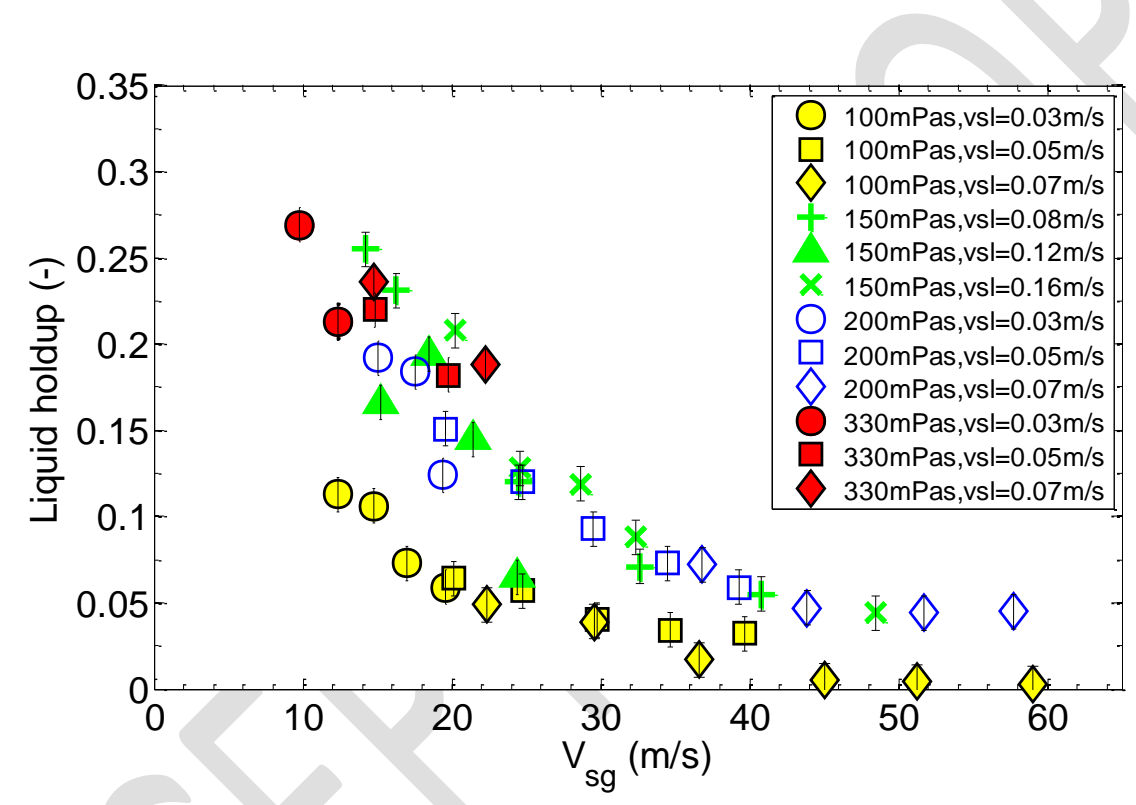

Figure 7: Variation of liquid holdup with superficial gas velocity for liquid viscosities of $100 \mathrm{mPa}$, $150 \mathrm{mPa}$ s, $200 \mathrm{mPa}$ and $330 \mathrm{mPa}$ s respectively at different $v_{s l}$ values 


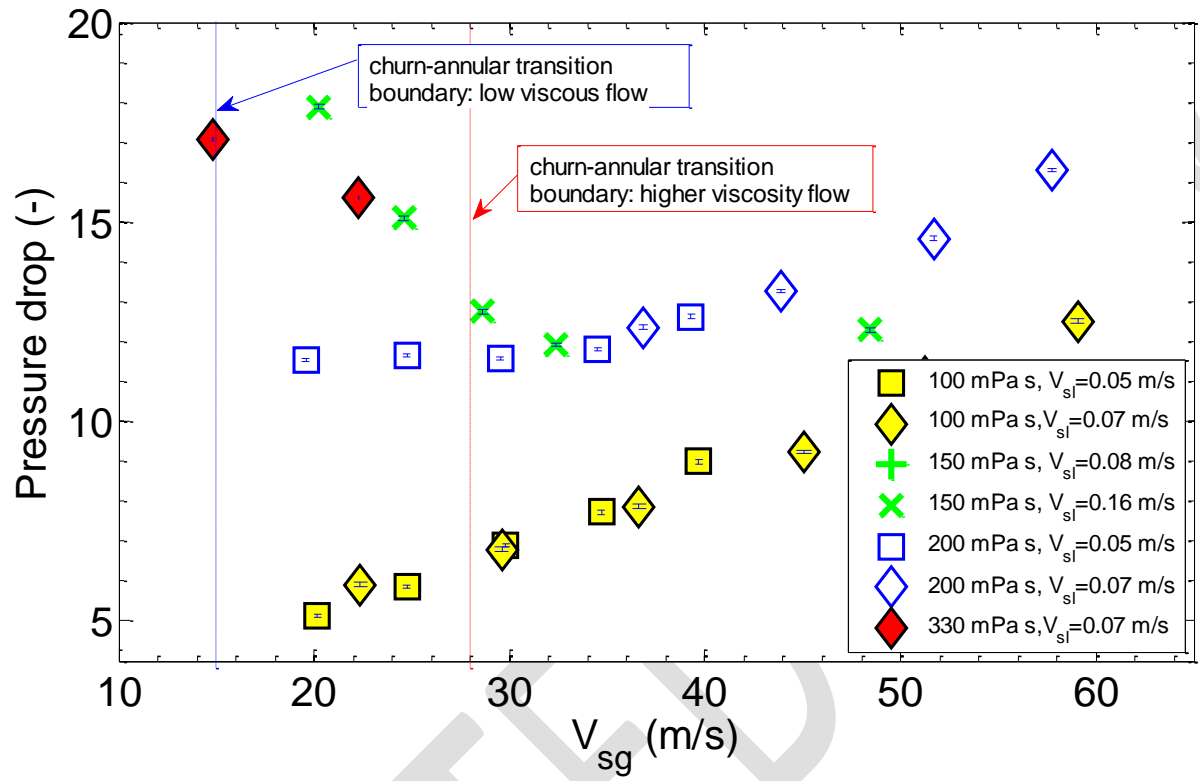

Figure 8: Variation of pressure drop with superficial gas velocity for liquid viscosities of $100 \mathrm{mPa}, 150,200$ $\mathrm{mPa} s$ and $330 \mathrm{mPa}$ s respectively at $v_{s l}$ values of 0.05 and $0.07 \mathrm{~m} / \mathrm{s}$ respectively. The blue vertical line represents transition to annular flow observed in water and other low viscosity liquids, marked by a turning point in the pressure drop vs $V_{s g}$ curve. The red vertical line represents transition to annular flow in the

higher viscosity oils. 


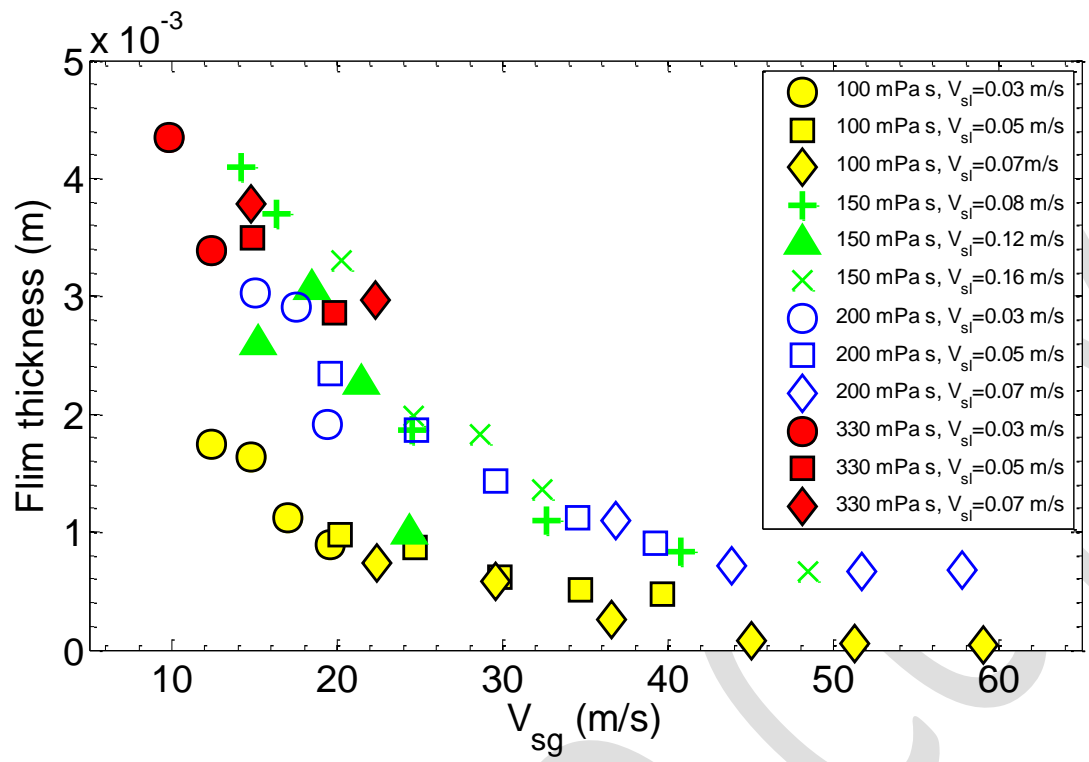

Figure 9: Variation of liquid film thickness with superficial gas velocity for liquid viscosities of $100 \mathrm{mPa}$ s, 200 $\mathrm{mPa} s$ and $330 \mathrm{mPa} s$ respectively at different superficial liquid velocities 
Published in Chemical Engineering Communications as Ribeiro et al.. https://doi.org/10.1080/00986445.2019.1647180 online on 29 August, 2019

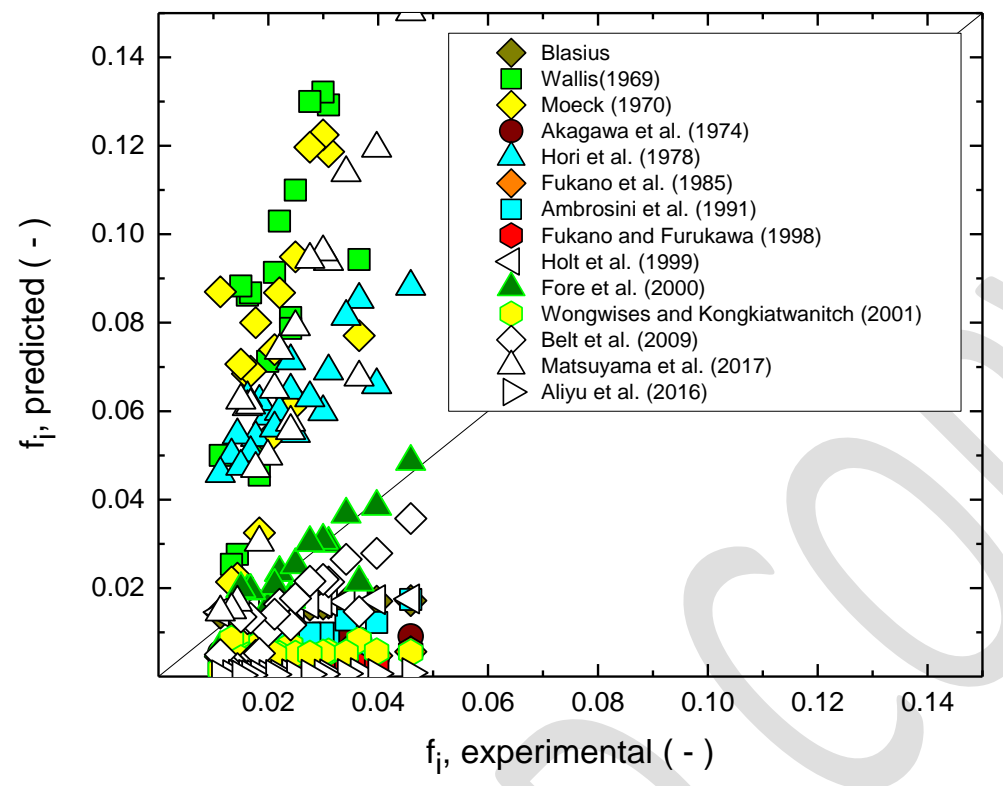

Figure 10: Pictorial assessment of predictions interfacial friction factor using selected correlations 
Published in Chemical Engineering Communications as Ribeiro et al.. https://doi.org/10.1080/00986445.2019.1647180 online on 29 August, 2019

(a)

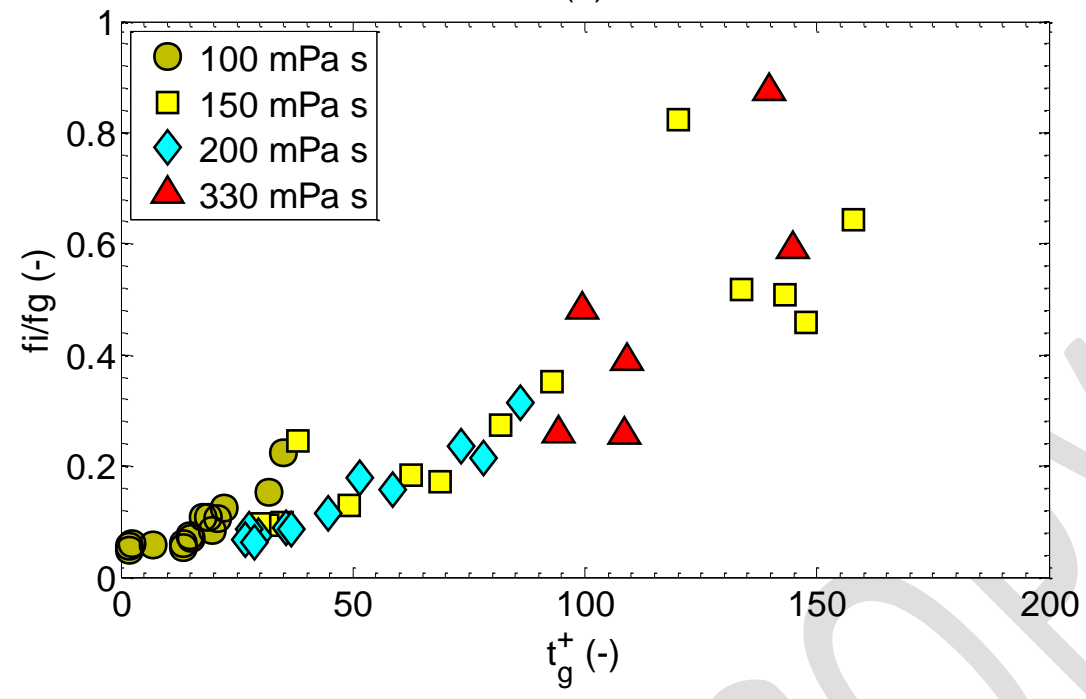

(b)

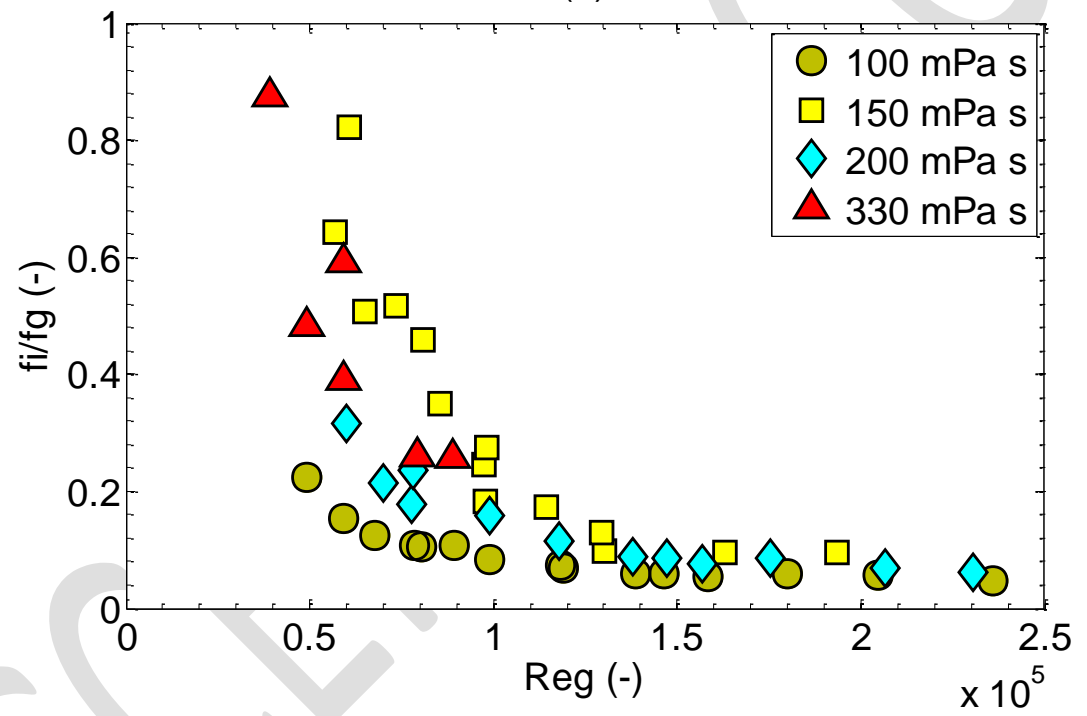

Figure 11: Effect of (a) $t_{g}^{+}$and (b) $R e_{g}$ on $\left(f_{i} / f_{g}\right)$ for various liquid viscosities 
Published in Chemical Engineering Communications as Ribeiro et al.. https://doi.org/10.1080/00986445.2019.1647180 online on 29 August, 2019

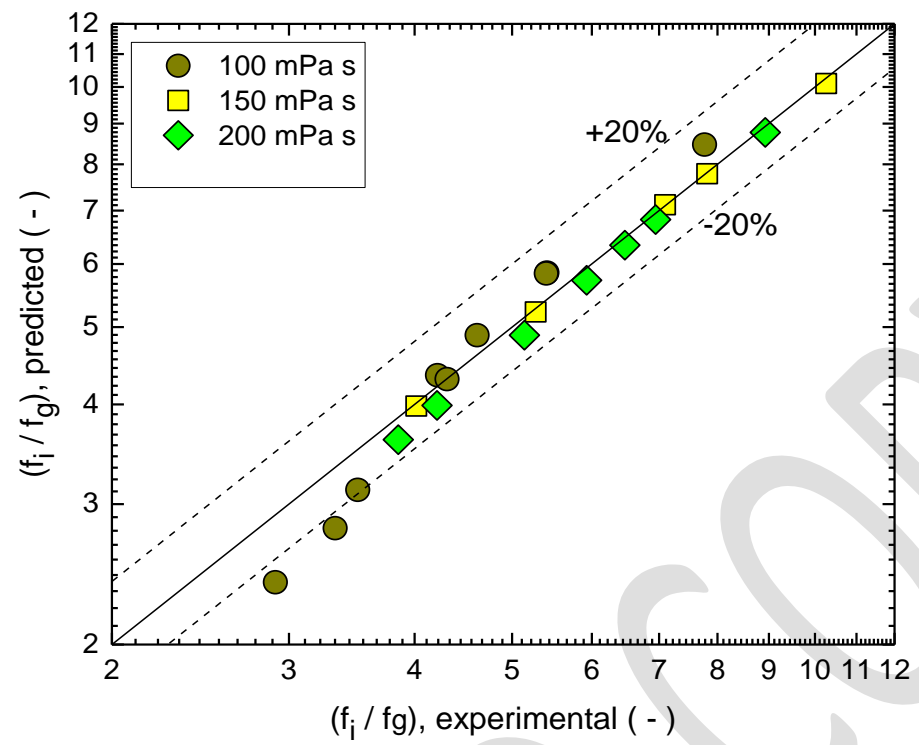

Figure 12: Comparison of the current experimental $\left(f_{i} / f_{g}\right)$ with predictions of the model (Eq.22) 
Published in Chemical Engineering Communications as Ribeiro et al.. https://doi.org/10.1080/00986445.2019.1647180 online on 29 August, 2019

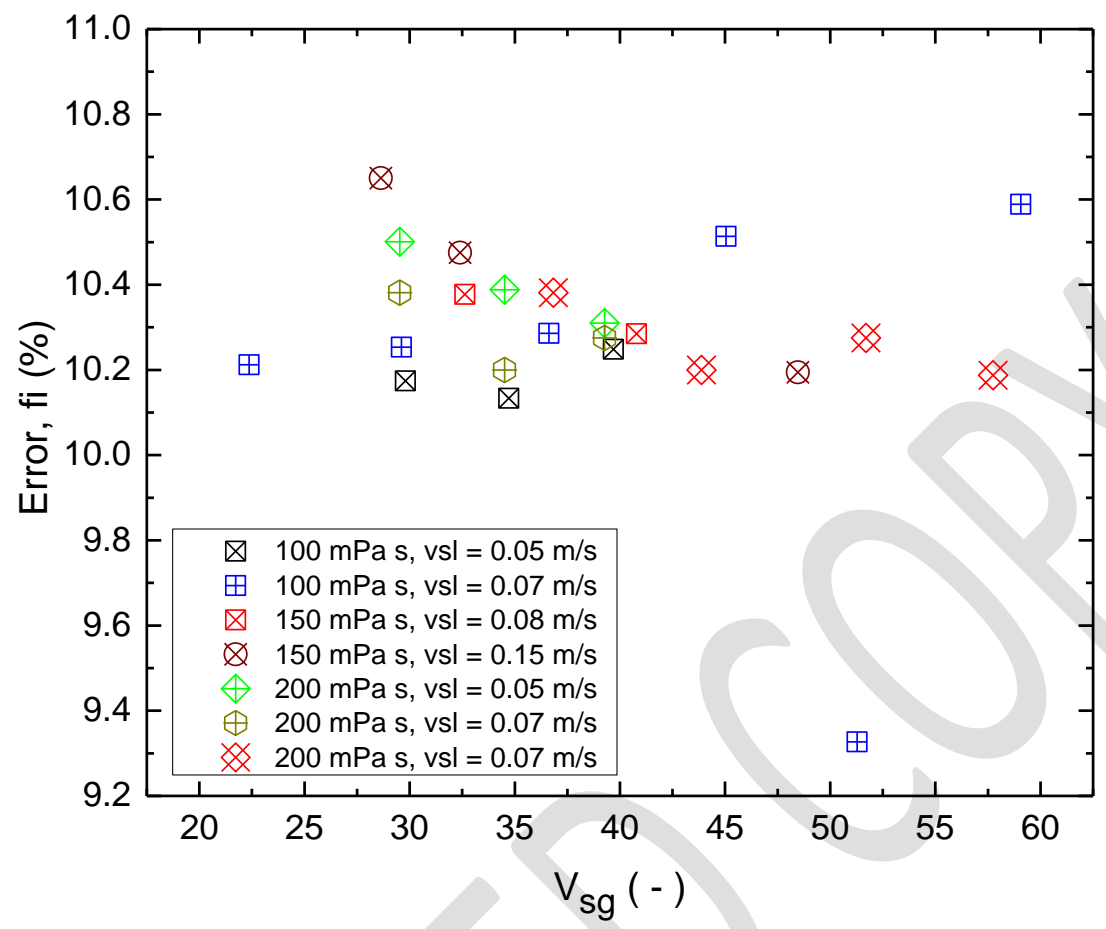

Figure 13: Percentage error in fi at different experimental conditions 


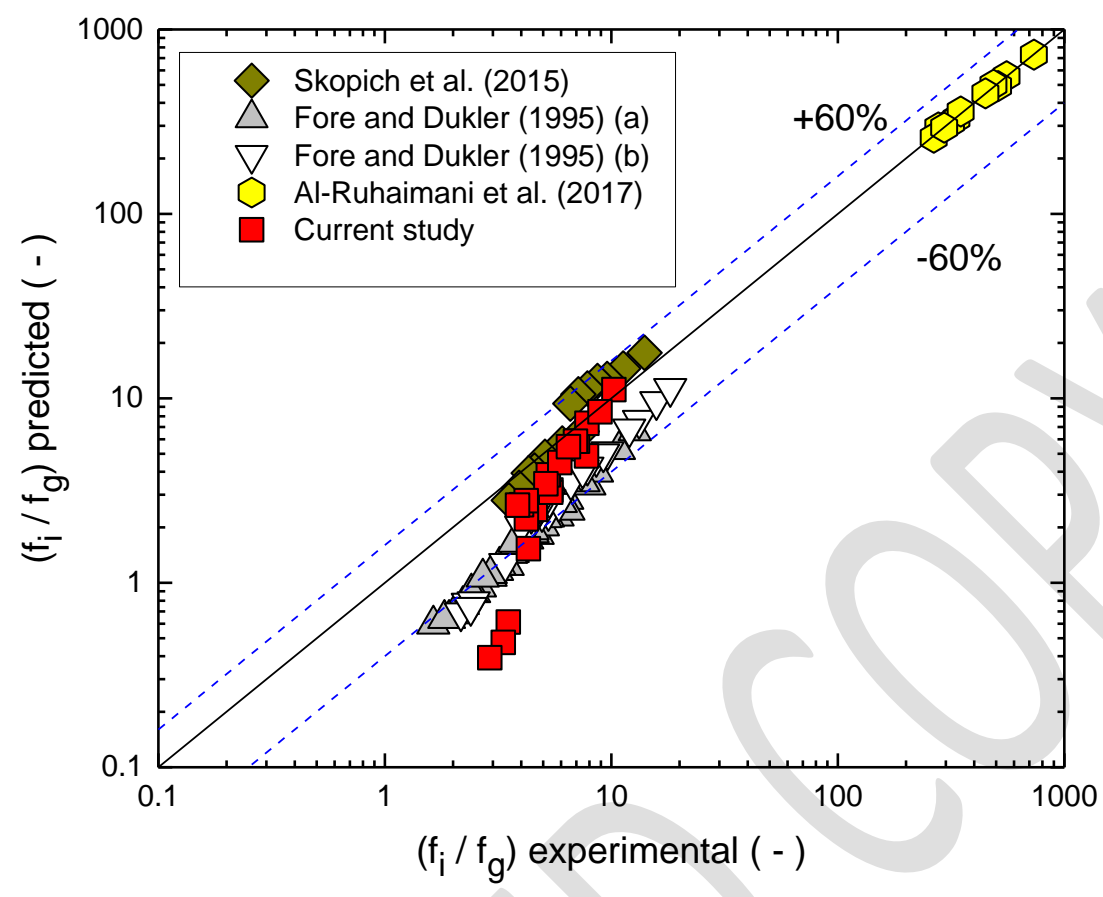

Figure 14: Comparison of the current experimental $\left(f_{i} / f_{g}\right)$ with predictions by the correlations of Skopich et al. (2015), Fore and Dukler (1995), and Al-Ruhaimani et al (2017) 


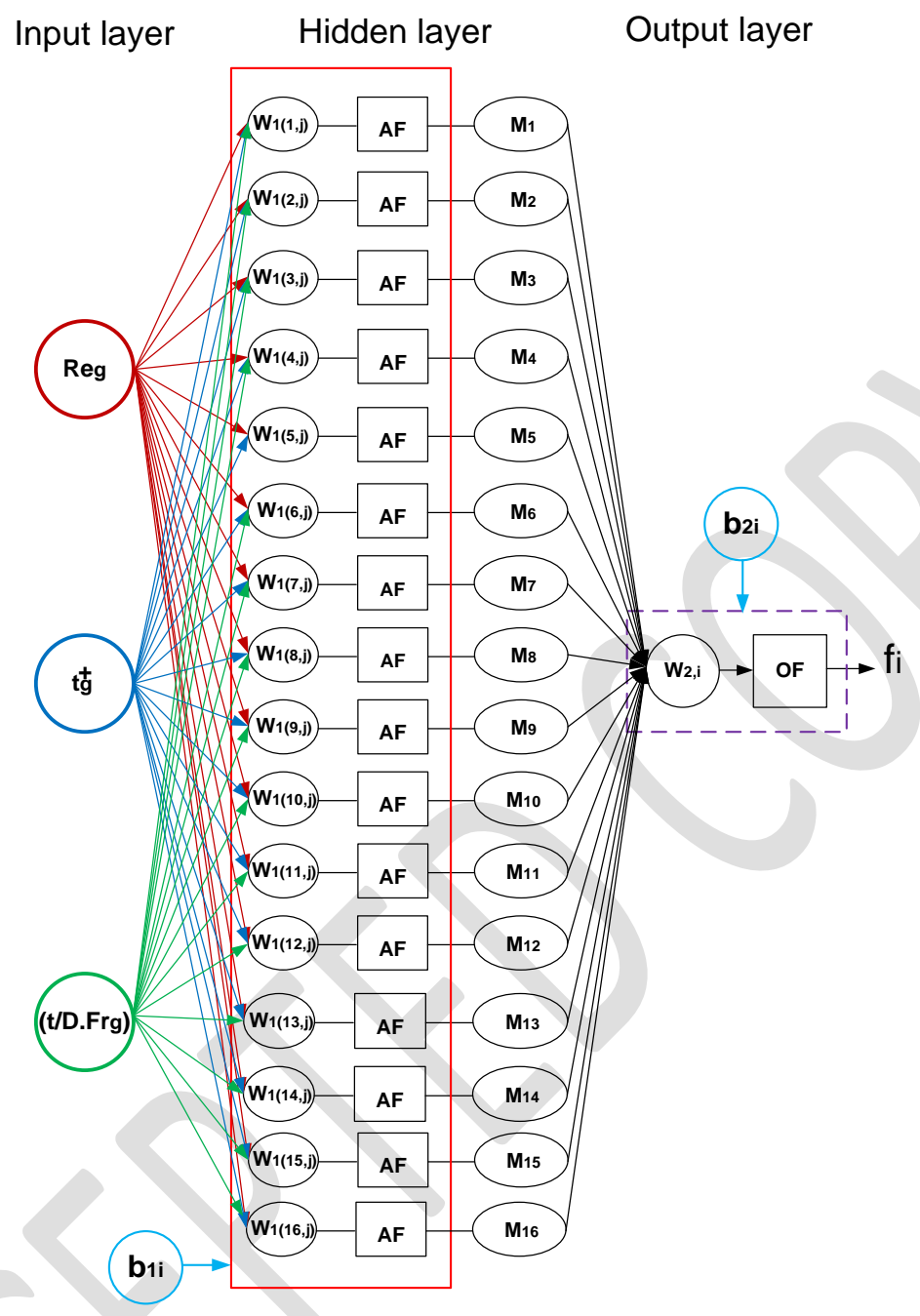

Figure 15. Schematic representation of the ANN architecture used in this study with 16 neurons for the prediction of interfacial friction factor 


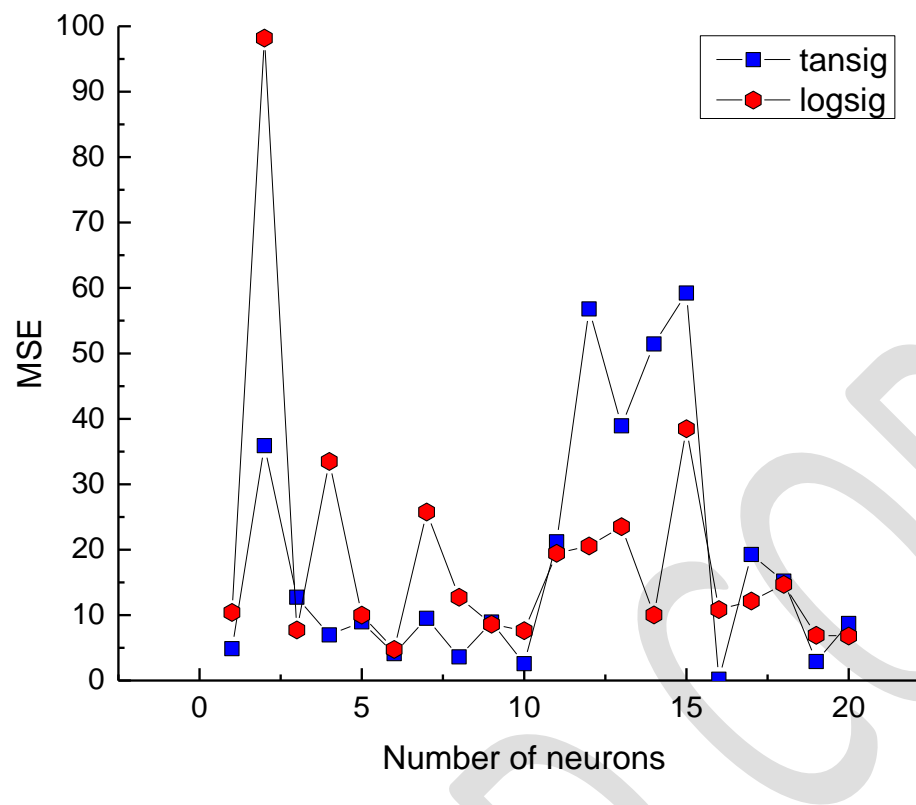

Figure 16: Performance of the testing data for the networks using tansig and logsig transfer functions for different neuron configurations in the hidden layer for interfacial friction factor 
Published in Chemical Engineering Communications as Ribeiro et al.. https://doi.org/10.1080/00986445.2019.1647180 online on 29 August, 2019

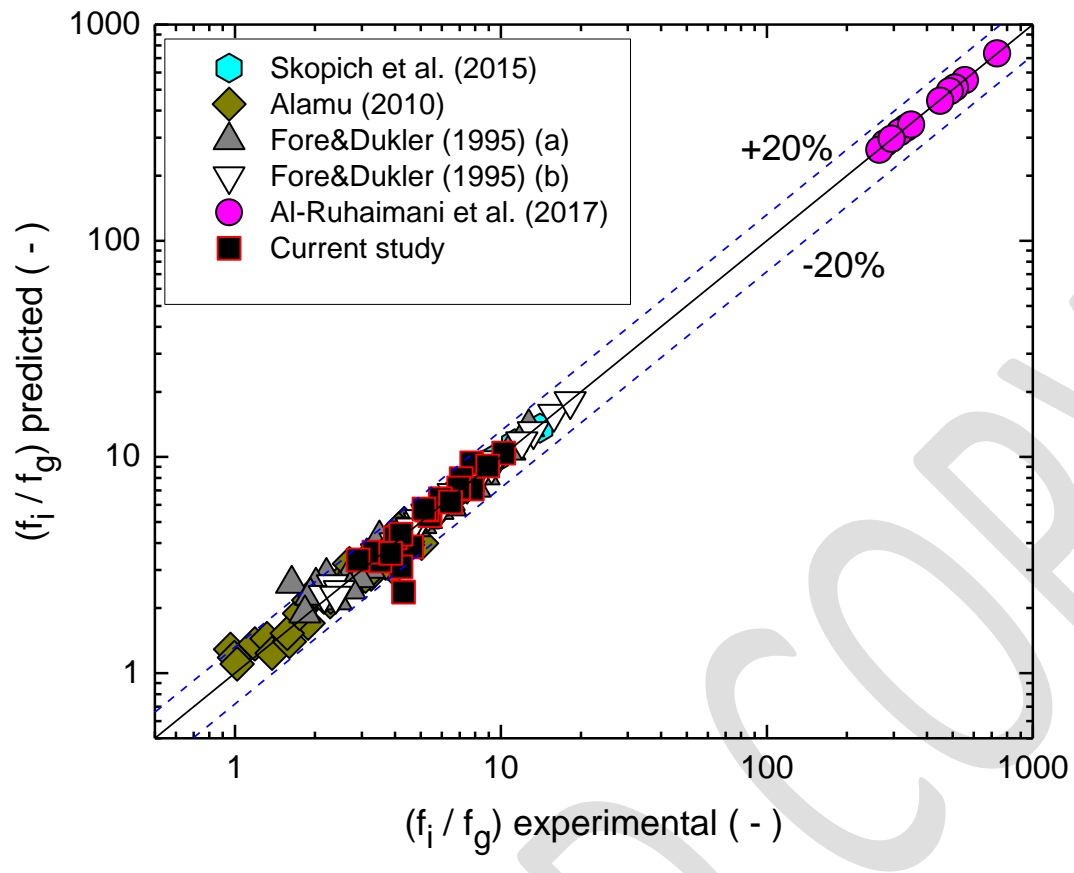

Figure 17: Cross-plot of experimental and $\left(f_{i} / f_{g}\right)$ predictions of the ANN model 